\title{
Seasonality of Food Use and Caching in New Zealand Robins (Petroica australis)
}

\author{
Jamie Ernest Sherred Steer
}

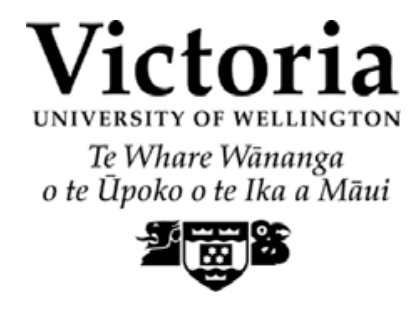

2006

A thesis submitted in partial fulfilment of the requirements for the degree of Master of Science in Ecology and Biodiversity. 


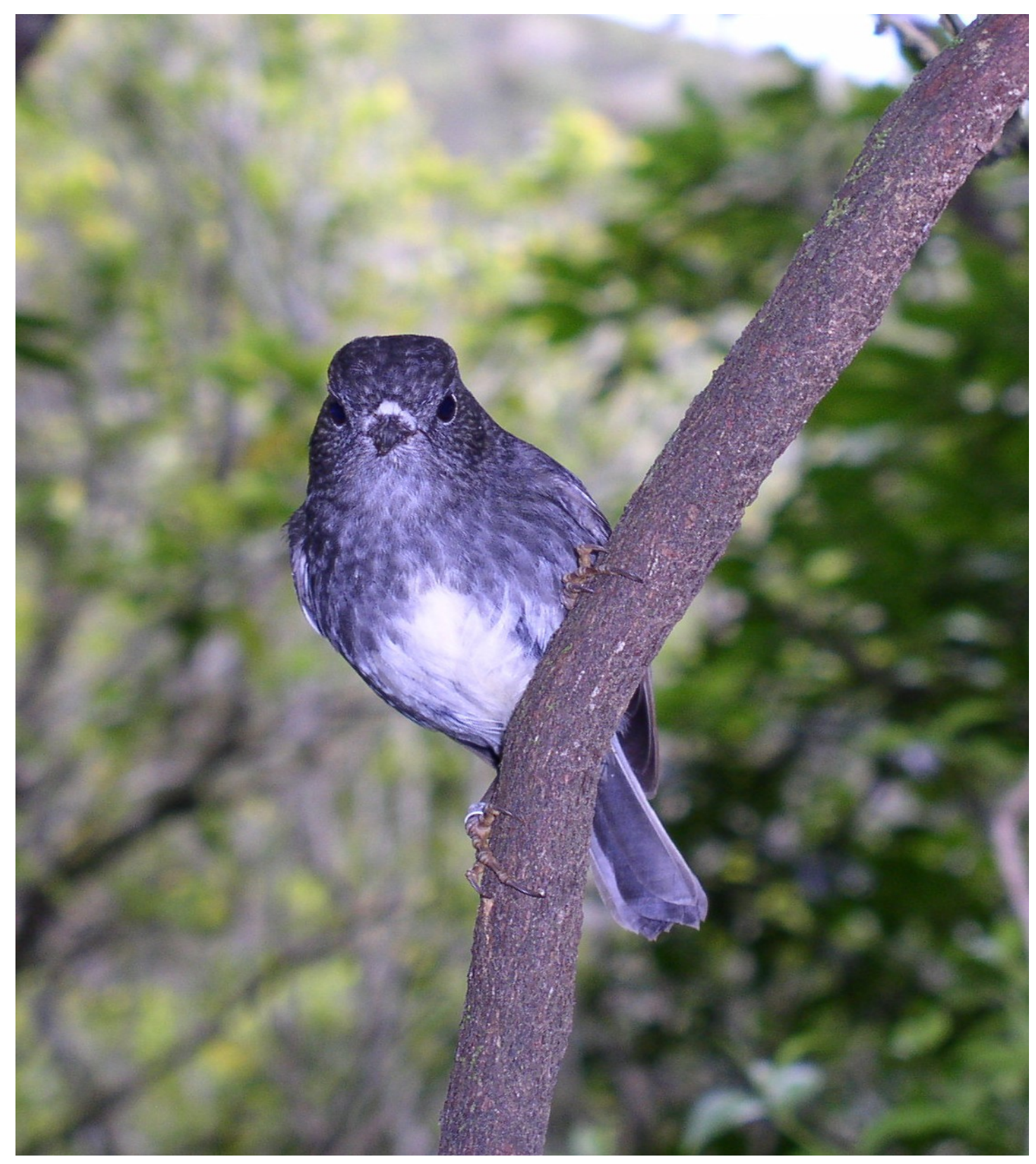

Figure 1: New Zealand Robin (Petroica australis) Photo: J. Steer. 


\section{ABSTRACT}

Foraging behaviour in birds is strongly determined by temporal factors such as season and time of day. Most birds show a limited number of food use methods such as consuming, feeding to conspecifics, or discarding. A relatively small number of birds also cache food for later use. The expression of caching in birds has been attributed to numerous factors. However, noting the environmental instability experienced by most caching species, researchers tend to cite survival of future food scarcity as the predominant advantage. Recording the food use behaviour of wild birds is typically difficult and time consuming, and many studies of north-temperate food-caching birds are limited by long caching distances, protracted caching durations, and a lack of year-round data. Additionally, food-caching in Australasian passerines has received limited quantification.

The naïveté of the New Zealand robin (Petroica australis) makes it ideal for behavioural observations in the wild. Robins express a wide range of food use behaviours within close proximity of observers, and cached food is retrieved within a few days. Food use can be observed year-round in a temperate environment that is relatively stable. Thus, food use decisions in robins can be assessed in a wider context. In this study, behavioural data were collected from robins inhabiting the Karori Wildlife Sanctuary in Wellington. Robin behaviour was quantified by presenting monogamous, paired birds an ephemeral food resource and observing their responses.

Seasonal variation in food use differed with sex and season. Birds mediated their food use in response to the presence of conspecifics. Males dominated food use year-round. During the breeding season, males cached little, mostly feeding familial 
conspecifics. However, non-breeding males selfishly cached food. Conversely, female caching propensity was mediated by courtship feeding during the breeding season, and the threat of male pilferage outside of it. Birds did not appear to anticipate future food scarcity. Instead, food was cached in the season in which retrieval would be least necessary. In robins, food is opportunistically cached, mainly as a competitive response to excess food. 


\section{ACKNOWLEDGEMENTS}

Here I would like to extend my gratitude to all the people who have helped me along the way. It has been a pivotal few years. Not only have I enjoyed watching these extraordinary little creatures, but I have also learnt an immense amount about the surrounding flora and fauna during many hours in the field.

Naturally, the primary source of inspiration and logistical support sprang from my tireless supervisor KC Burns. This project was itself a suggestion of his. We have spent many hours talking over problems and discussing solutions. Unfortunately, he appears to have aged considerably during this process (van Horik 2006).

Many thanks to everyone else at the university for support and encouragement. Especially to Lloyd Stringer, with whom I was able to compare my progress, and subsequently reason that things 'weren't so bad after all'. Thanks for the perspective. Seriously, Marc Hasenbank, Andrew Martin, Shirley Pledger, and Jayden van Horik were all important influences.

All the staff and volunteers at the Karori Wildlife Sanctuary have been a big help. I have really appreciated the advice and suggestions of Raewyn Empson and Matu Booth. Observations of behaviour during the breeding season were enhanced by comparing notes with the ‘robin group’: Frances Gazley, John Geale, Annette Harvey, Melanie Mills, and Faye Schaef.

Finally, I thank friends and family for all the good things in life, and for helping me to think about other things. Elizabeth Murray, you are my favourite person. 


\section{TABLE OF CONTENTS}

Abstract _ ii

Acknowledgements ___ iv

Table of contents __ $\mathrm{v}$

List of figures __ vii

CHAPTER ONE: GENERAL INTRODUCTION _ 01

Food use and caching in birds ......................................... 01

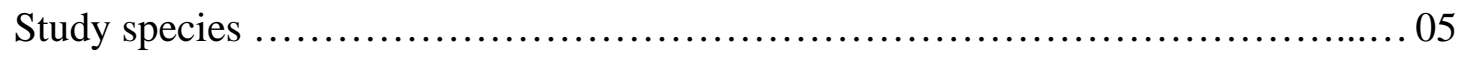

Food use and caching in New Zealand robins .............................. 08

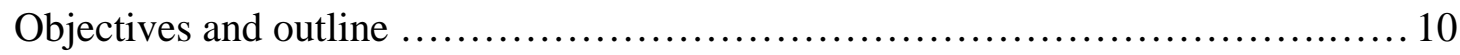

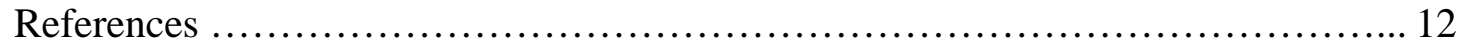

CHAPTER TWO: SEASONALITY OF FOOD USE AND CACHING _ 16

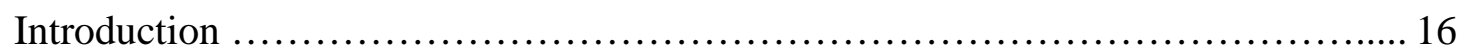

Methods ........................................................................ 21

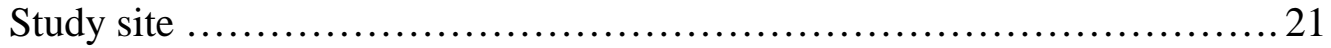

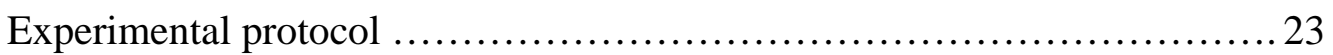

Data analysis .................................................... 29

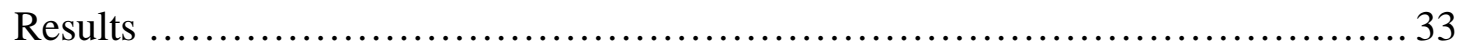

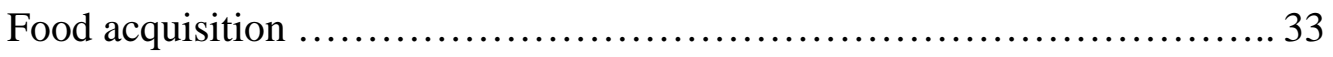

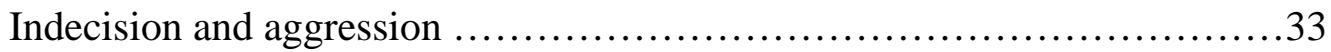

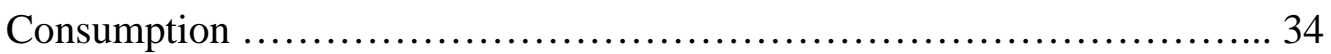

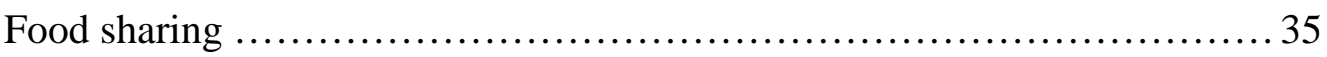


Caching ............................................................ 36

Number of cache sites ...................................... 37

Number of caching flights ..................................... 38

Retrieval .......................................................... 38

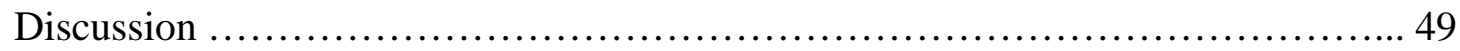

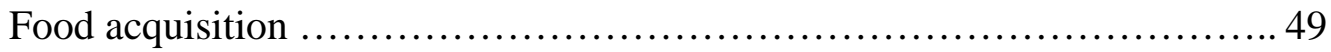

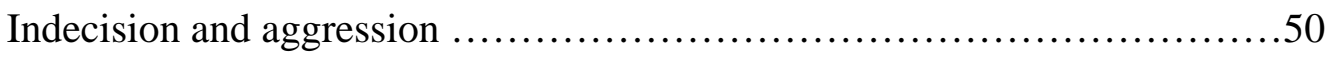

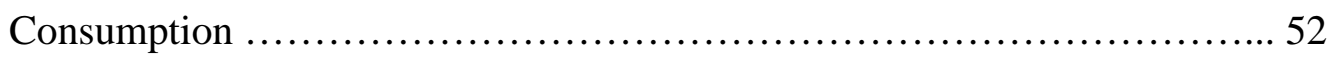

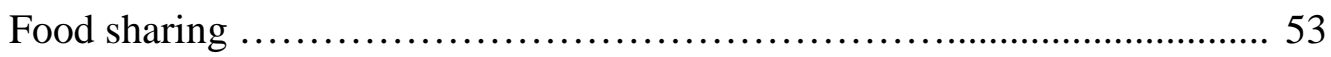

Caching ............................................................ 55

The effect of food availability on caching $\ldots \ldots \ldots \ldots \ldots \ldots \ldots \ldots \ldots . \ldots 56$

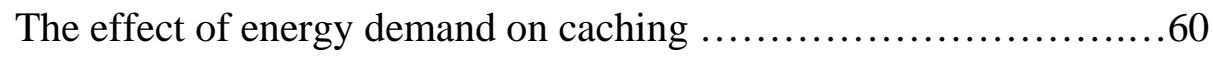

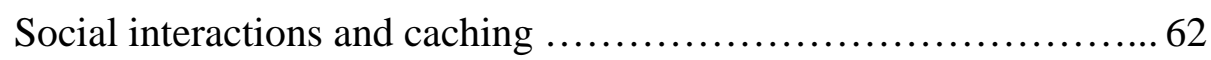

Retrieval ...................................................... 66

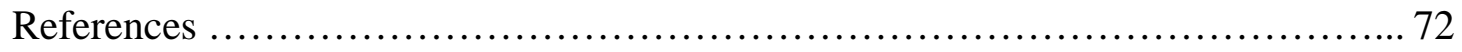

CHAPTER THREE: SUMMARY AND CONCLUSIONS _ 79

Seasonality of food use and caching in New Zealand robins .................... 79

Competition and caching behaviour ................................ 80

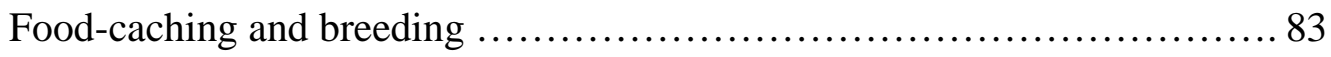

The evolution of food-caching behaviour in New Zealand robins ................. 87

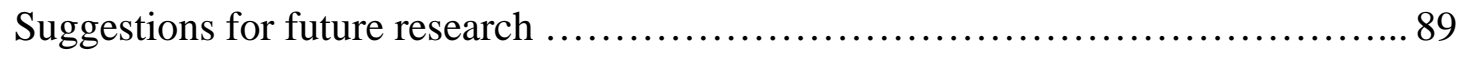

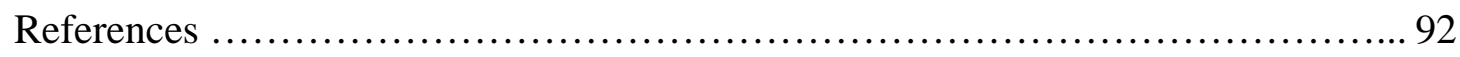




\section{LIST OF FIGURES}

Fig. 1: New Zealand Robin (Petroica australis) ................................ i

Fig. 2: Map of the Karori Wildlife Sanctuary ............................... 22

Fig. 3: Comparison of monthly temperature variation between the Karori Wildlife Sanctuary, Wellington (New Zealand), and Salem, Oregon (United States of America) .............................................................. 23

Fig. 4: Seasonal and intersexual variation in robin mealworm acquisition .......... 39

Fig. 5: Seasonal variation in time taken for robins to use mealworms 40

Fig. 6: Seasonal variation in male robin indecision and aggression 41

Fig. 7: Seasonal and intersexual variation in robin mealworm consumption 42

Fig. 8: Seasonal variation in male robin courtship feeding 43

Fig. 9: Seasonal and intersexual variation in robin juvenile feeding 44

Fig. 10: Seasonal and intersexual variation in robin mealworm caching 45

Fig. 11: Seasonal and intersexual variation in the number of cache sites made by robins 46

Fig. 12: Seasonal and intersexual variation in the number of caching flights made by robins 47

Fig. 13: Seasonal and intersexual variation in robin cache retrievals 48 


\section{CHAPTER ONE}

\section{GENERAL INTRODUCTION}

\section{Food use and caching in birds}

Birds use food in a variety of different ways. Captured food can be consumed, moved, cached, fed to a conspecific, or discarded. However, different species often respond to the same food source in different ways, and intraspecific variation is also widespread. Food use behaviour may vary according to age (Maccarone 1987; Brooke \& Birkhead 1991), sex (Glase 1973), season (Hutto 1981; Wheelwright 1986), and social condition (Daily \& Ehrlich 1994). In addition, there can be plasticity in food use among geographically dispersed conspecifics (Kramer 2001). For instance, previous research has provided evidence for variation associated with latitudinal climatic constraints (Lima 1986; Brodin et al. 1996) and with localised habitat types (Powlesland 1981b). The use of food by an individual, therefore, is determined by a combination of species specific and individual specific mediators.

Consumption, either personally or by a familial conspecific, is the primary objective of all food handling activities (see Kramer 2001). Relative to mammalian teeth, the beak is a poor instrument of mastication. Therefore, birds consume prey after little manipulation, leaving the process of digestion to the alimentary canal (Brooke \& Birkhead 1991). In the absence of competitors, the speed of consumption is largely determined by the size and nature of prey. Small items tend to be rapidly ingested, while larger items may take longer, having to be broken up before being swallowed. The influence of competition for food, or potential for it, also plays a 
significant role in the nature of consumption (Stone \& Baker 1989). For instance, the presence of competitors or predators mean that food is generally consumed with some haste, either to avoid pilferage of food, or to escape predation (Elgar 1989; Onuki et al. 2005; Onuki \& Makino 2005). In response to this threat, many birds remove large prey items from the point of acquisition to consume inconspicuously. Reproductive requirements may also influence consumption patterns (Lahti \& Rytkönen 1996). During breeding, male birds often court females with offers of food, or directly feed nestlings. In any case, additional food is rarely deserted.

An unusual feature of some birds is the ability to cache food. Food-caching (hoarding and storing are synonymous terms) is broadly defined as the handling of food to conserve it for future use (Vander Wall 1990). Caching involves a process of preparation, transport, placement, and concealment in which the location of an item of food is rearranged in time and space (see Vander Wall 1990). In the literature, foodcaching is widely explained as: a response to competition/predation when faced with food excess; a response to even out fluctuations in food supply (scarcity); or as an alternative to fat storage (in Lucas \& Walter 1991). Put simply, food-caching is a response to an overabundance of food (see Gerber et al. 2004; Deschênes et al. 2005; Pravosudov 2006). Food scarcity is regularly faced by animals, including non-caching species. However, food excess, especially that which is able to be cached, may be uncommon.

Once an animal is satiated, any additional food is available for alternative uses. In general, extra food can be consumed, guarded, deserted, or cached. The latter may be advantageous as a way of reducing the costs of consumption. Consuming food over 
and above requirements increases fat stores which may result in reduced competitive ability, or an increase in predation (Smith \& Reichman 1984; Pravosudov \& Lucas 2000; Lundberg \& Brodin 2003). Guarding food may be similarly expensive, especially for small passerine birds. Deserting food, on the other hand, facilitates advantages to competitors (Tinbergen 1953). Food is often able to be cached at relatively little energetic cost, allowing the caching individual to exercise temporal control over their consumption patterns (Dally et al. 2006). Time may then be allocated to consuming when it is profitable, such as when predatory risk is low (Sherry 1985).

Despite the apparent utility of caching food, the behaviour is absent from the majority of species. Therefore, the conditions promoting the continuation of caching are unlikely to be commonplace. Non-caching species have presumably either lost the ability, never acquired it, or are somehow unable to derive significant advantage from the practice. However, among caching species, it may be integral to survival. For this reason there is now an extensive literature available on the food-caching patterns of many bird species (see Sherry 1985; Vander Wall 1990; Milius 2004). In the last forty years, especially, there has been acceleration in the amount of interest in this topic and this has lead to an increase in the quantity of published work. In previous studies, the evolutionary utility of the behaviour has been attributed to: increasing survivorship during food scarcity, optimizing foraging strategies, mate advertising, invoking competitive advantage, predator avoidance, and increasing the survivorship of young (see Vander Wall 1990). However, these motives may not be mutually exclusive. Lucas and Walter (1991) contended that predictions concerning which of these factors is most important in the expression of caching behaviour should be possible. 
Food-caching birds generally disperse their caches widely (scatter hoarding) (Dally et al. 2006) by placing few items of food in many disparate locations; although some, such as owls (Strigidae and Tytonidae) and acorn woodpeckers (Melanerpes formicivorus), will cache many items in a single or few locations (larder hoarding) (Vander Wall 1990). The pattern of storage employed by an animal seems to be related to its ability to defend caches against competitors (Stapanian \& Smith 1978). In some species, only one of the sexes caches (Yosef \& Pinshow 1989), while, in others, caching propensity may increase with age (Lens 1994). The majority of species retrieve food quickly (usually $<10$ days), undertaking food-caching yearround (Vander Wall 1990). Retrieval of cached food is facilitated by spatial memory (Cowie et al. 1981; Emery et al. 2004), although this may be enhanced by caching only in favoured sites (Anderson \& Krebs 1978). Most birds cache their prey in trees rather than bare soil or rock. The selection of cache sites may reflect the most secure caching location, or simply the habit to which a bird is accustomed.

Of more than 8,000 bird species (May 1988) less than 2\% are known to cache food (pers. obs.). However, in some species that are not known food cachers, activities approximating caching behaviour have occasionally been encountered (Smith \& Reichman 1984). Most food-caching passerines, either solely or partially, cache seeds. Some well known food-caching birds include jays, crows, and nutcrackers (Corvidae); tits and chickadees (Paridae); hawks (Falconidae, Accipitridae, and Sagittariidae); owls; shrikes (Laniidae); nuthatches (Sittidae); Australian butcherbirds (Craticidae); bowerbirds (Ptilonorhynchidae); and 
woodpeckers (Picidae) (Vander Wall 1990). Many insects and mammals are also conspicuous food cachers.

\section{Study species}

This study was conducted over two consecutive years on New Zealand robins (Petroica australis, hereafter 'robins') (Fig. 1) inhabiting the Karori Wildlife Sanctuary (KWS) in Wellington, New Zealand. The robin is a small, endemic passerine comprised of three subspecies, each restricted to one of the main islands and its outliers (Heather \& Robertson 2005). These are the North Island robin (ssp. Longipes, including the KWS population), South Island robin (ssp. australis), and Stewart Island robin (ssp. rakiura). Most behavioural research has been conducted on longipes and australis, with little research on rakiura.

Robins weigh only about 35g, but are considerably larger than their other native congenerics, the New Zealand tomtit (Petroica macrocephala) and the black robin (Petroica traversii). Both sexes measure around $18 \mathrm{~cm}$ in length and have a bold upright stance accentuated by long thin legs. The plumage is mostly grey-black with a whitish breast, varying in prominence with sex and subspecies (Higgins \& Peter 2002). Males have darker plumage on their back and upper breast (Armstrong 2001). However, sexes differ only slightly in adults and may only be separable by observing behavioural interactions between conspecifics. Males show delayed plumage maturation (Armstrong 2001). They acquire characteristic male plumage after their first breeding season, 12 to 16 months after fledging. Immature birds may also be difficult to distinguish from adults when viewed in isolation. The retention of relatively light coloured plumage to adulthood in robins is characteristic of immaturity 
in most Petroica spp. (Fleming 1950b). Birds show no seasonal variation in plumage, other than during the moult which occurs around late summer. During this time, individuals are often missing prominent feathers such as retrices.

Robins are not difficult to locate and study in the wild (Powlesland 1981; Armstrong et al. 2000; Burns \& van Horik 2006). Despite this, previous behavioural research on robins is dominated by a relatively small number of investigators (especially Armstrong, Flack, and Powlesland; see references). Robins are highly inquisitive, and readily inspect human activities within their territory (Buller 1888; Soper 1984). Birds are attracted to any disturbance in the leaf litter (Heather \& Robertson 2005), leading to speculation that they may have benefited from disturbances created by roaming or grazing moa (Atkinson \& Millener 1990). Robins hold their territories year-round (Moncrieff 1932; Flack 1975), except for a brief period during the moult (Soper 1976). They are highly territorial (Powlesland 1980) and are often aggressive toward encroaching heterospecifics (Moncrieff 1931; Higgins \& Peter 2002). However, they are especially aggressive toward unfamiliar conspecifics (Soper 1976). Male birds are socially dominant to females (Flack 1976; Burns \& Steer 2006) and are frequently aggressive towards their mates (Powlesland 1981b).

Most birds remain monogamous for life (Armstrong et al. 2000). Breeding commences at the age of 1 year, with males beginning courtship feeding as early as July (Heather \& Robertson 2005). Armstrong et al. (2000) found that the breeding season generally lasted for about six months - from September to February. Initial clutches are laid in late-September with the last clutches lain by mid-November 
(Armstrong et al. 2000). The earliest and latest clutches recorded occurred in midAugust and early-January respectively (Armstrong et al. 2000). The female builds the nest alone with the male feeding her on average 3.2 times per hour (Powlesland 1983b). During incubation, the female is called off the nest by the male and fed 20 to 50m away a further 2 to 3 times per hour (Heather \& Robertson 2005). Courtship feeding by the male mostly terminates after the hatching of offspring (Powlesland 1983b; Alexander et al. 2005).

Both birds feed the nestlings (Heather \& Robertson 2005). However, if the female begins re-nesting the male takes full responsibility. Juveniles begin foraging around 2 weeks after leaving the nest (Heather \& Robertson 2005). Single fledglings are cared for by the male. If there are two or more fledglings, the parents divide care of the brood (Heather \& Robertson 2005). They are fed by their parents for 25 to 50 days before being encouraged to leave the territory (Powlesland 1983b). Usually all fledglings are independent by late-February (Armstrong et al. 2000). The latest time that a fledgling was recorded receiving food from its parents was mid-March (Armstrong et al. 2000).

Like many New Zealand bird species, the robin population has suffered a severe contraction since pre-human times (Bell 1990). Human induced deforestation and the introduction of exotic mammals have had a profoundly negative impact on robins (see also Diamond \& Veitch 1981). By the early 1900’s environmental degradation had lead to the extinction of robins in the lower North Island (Heather \& Robertson 2005), and the species is currently listed in the IUCN Red List of Threatened Species (BirdLife International 2004). However, during 2001-02 robins 
were reintroduced to the KWS from a nearby population on Kapiti Island (Miskelly et al. 2005). The species has thrived within the sanctuary, breeding prolifically and rapidly expanding its territory. Close monitoring of the species' breeding success was undertaken during its first 5 years in residence, but was deemed unnecessary thereafter. The habitat structure provided by the KWS seems to be conductive to robins, closely resembling that preferred by wild populations in other parts of the country.

\section{Food use and caching in New Zealand robins}

Robins are primarily insectivorous, spending $90 \%$ of their foraging time on or within two metres of the ground (Powlesland 1981). Ground gleaning and scanning comprise the majority of foraging time, although robins also glean from vegetation, hawk, and flycatch. In summer and autumn some berries are taken (Powlesland 1981). Food is generally used by robins in one of three ways, either consumed, cached, or fed to conspecifics (i.e. juveniles or mates). The latter is associated with reproduction, occurring commonly during breeding. Consumption occurs year-round, but caching appears to be infrequent during breeding (Powlesland 1980).

When faced with a temporary abundance of food, robins commonly respond by caching a portion of it. Generally, only large invertebrates such as earthworms and cicadas are cached. Smaller items are consumed immediately. Large prey is commonly broken up, with a small portion being consumed before caching. Many cached items suffer from puncture wounds and/or burst abdominal cavities which, when coagulated, may adhere them to the cache site (Powlesland 1980). Most items 
are transported less than 10m from the point of acquisition (Powlesland 1980). Items are cached above ground level, transported via flight. The average cache site is $2.8 \mathrm{~m}$ in height, usually in a branch axil, stump end, branch hole, or tree fern frond axil (see also Powlesland 1980). Caching rarely takes more than a minute, and most items are cached in about 24 seconds (Powlesland 1980). Both sexes cache food, although the threat of male pilfering generally causes females to move out of sight of the male before caching (Higgins \& Peter 2002). Powlesland (1980) found that robins sometimes foraged outside of their territory during autumn, but food was always cached close to where it was found.

Cache duration is short, and food is usually retrieved within about 1 to 3 days. The short interval between caching and recovery in robins might be related to the fast rate of spoilage of invertebrate prey cached under moist, warm conditions (see Powlesland 1980). Alternatively, recovery may simply coincide with the rate of digestion. Robins cache food throughout the day. However, most food is cached during the morning with retrieval mostly after mid-afternoon (Powlesland 1980). Retrieval of cached food is seen infrequently. Of 40 cached items monitored by Powlesland (1980), 58\% disappeared within the day, but the cause was not determined. Robins show no attempt to conceal their caches (Powlesland 1980; Alexander et al. 2005) and cached items are often visible from above (Powlesland 1980). Powlesland (1980) observed instances in which either sex immediately ate the cached food of their mate. Occasionally food was taken and then re-cached. Cached prey may also be susceptible to interspecific pilferage by birds (Steer \& van Horik unpublished manuscript) or insects (Barr et al. 1996). Detailed cognitive information, 
such as how robins find caches, and how many cache sites birds are able to recall, is currently lacking.

The food use behaviour of Petroica australis longipes is mostly consistent with $P$. australis australis (Alexander et al. 2005). However, one unexplained source of variation is found in the cache dispersion of longipes relative to australis. Alexander et al. (2005) found that longipes often cached numerous mealworms in a single cache site, while australis rarely used the same site more than once (see Powlesland 1980). However, this variation may correspond with differences in observational procedures. Alexander et al. (2005) offered wild robins an extra source of food, while Powlesland (1980) observed birds undertaking their natural foraging behaviour. There has been no systematic attempt to compare the food use behaviour of the three robin subspecies.

\section{OBJECTIVES AND OUTLINE}

This research seeks to document seasonal variation in robin food use. By comparing results with the behaviour of other birds this study will aid in the investigation of food use in other bird species; particularly those that are difficult to accurately quantify because of extensive cache dispersion and/or secretive behavioural tendencies. Chapter 2 will outline an experimental analysis of food use. Specifically, data were collected to test for seasonal variation in food use. Data were also used to test whether seasonal patterns in food use differed between sexes. The number and proportion of food allocated to each use (e.g. consuming, caching etc) was quantified, along with the behaviours exhibited in association with these. Data analyses tested for seasonal variation in the number of prey items acquired, consumed, and fed to conspecifics. In 
addition, analyses tested variation in food handling time, number of cache sites, number of caching flights, number of cache retrievals, and for the frequency of aggressive and indecisive behaviour. Chapter 3 summarises these results, interpreting how conclusions from this study may relate to other food-caching bird species. The thesis concludes with a discussion of how food-caching may have evolved in robins and provides some suggestions for future investigation. 


\section{REFERENCES}

Alexander, L., C. Duthie, et al. (2005). "An experimental evaluation of food hoarding by North Island robins (Petroica australis longipes)." Notornis 52: 138-142.

Anderrson, M. and J. Krebs (1978). "On the evolution of hoarding behaviour." Animal Behaviour 26: 707-711.

Armstrong, D. P., J. G. Ewen, et al. (2000). "Breeding biology of North Island robins (Petroica australis longipes) on Titirangi Matangi Island, Hauraki Gulf, New Zealand." Notornis 47: 106-118.

Armstrong, D. P. (2001). "Sexing North Island robins (Petroica australis longipes) from morphometrics and plumage." Notornis 48: 76-80.

Atkinson, I. A. E. and P. R. Millener (1990). An ornithological glimpse into New Zealand's pre-human past. Acta XX Congressus Internationalis Ornithologi

Barr, K., H. Moller, et al. (1996). "Impacts of introduced common wasps (Vespula vulgaris) on experimentally placed mealworms in a New Zealand beech forest." Oecologia 105(2): 266-270.

Bell, B. D. (1990). Recent avifaunal changes and the history of ornithology in New Zealand. Acta XX Congressus Internationalis Ornithologici.

BirdLife International. (2004). “Petroica australis.” In: IUCN 2006. 2006 IUCN Red List of Threatened Species, from http://www.iucnredlist.org.

Brodin, A., K. Lahti, et al. (1996). "A northern population of willow tits Parus montanus did not store more food than southern ones." Ornis Fennica 73: 114118.

Brooke, M. and T. Birkhead, Eds. (1991). The Cambridge encyclopedia of ornithology. Cambridge, Cambridge University Press.

Buller, W. L. (1888). A history of the birds of New Zealand. London.

Burns, K. C. and J. Steer (2006). "Dominance rank influences food hoarding in New Zealand robins Petroica australis." Ibis 148: 266-272

Burns, K. C. and J. van Horik (2006). "Sexual differences in food re-caching by New Zealand robins." Journal of Avian Biology In press.

Cowie, R. J., J. R. Krebs, et al. (1981). "Food storing by marsh tits." Animal Behaviour 29: 1252-1259.

Daily, G. C. and P. R. Ehrlich (1994). "Influence of social status on individual foraging and community structure in a bird guild." Oecologia 100(1-2): 153165. 
Dally, J. M., N. S. Clayton, et al. (2006). "The behaviour and evolution of cache protection and pilferage." Animal Behaviour In press.

Deschênes, J., G. Desrosiers, et al. (2005). "Environmental influence on activity levels and behavioural allocation in the polychaete Nereis virens (Sars)." Journal of Experimental Marine Biology and Ecology 317: 203-212.

Diamond, J. M. and C. R. Veitch (1981). "Extinctions and introductions in the New Zealand avifauna: Cause and effect?" Science 211: 499-501.

Elgar, M. A. (1989). "Predator vigilance and group size in mammals and birds: A critical review of the empirical evidence." Biological Review 64: 13-33.

Flack, J. A. D. (1975). "Aspects of the ecology of the New Zealand robin Petroica australis." Emu 74(Supplement): 286.

Fleming, C. A. (1950b). "New Zealand flycatchers of the genus Petroica Swainson (Aves): Part II." Transactions of the Royal Society of New Zealand 78(2-3): 127-160.

Gerber, L. R., O. J. Reichman, et al. (2004). "Food hoarding: future value in optimal foraging decisions." Ecological Modelling 175: 77-85.

Glase, J. C. (1973). "Ecology of social organization in the black-capped chickadee." The Living Bird 12: 235-267.

Heather, B. D. and H. A. Robertson (2005). The field guide to the birds of New Zealand. Auckland, Penguin Books Ltd.

Higgins, P. J. and J. M. Peter (2002). Handbook of Australian, New Zealand and Antarctic birds. Volume 6: pardalotes to shrike-thrushes. Victoria, Oxford University Press.

Hutto, R. L. (1981). "Seasonal variation in the foraging behavior of some migratory western wood warblers." The Auk 98(765-777).

Kramer, D. L. (2001). Foraging behavior. Evolutionary ecology: concepts and case studies. C. W. Fox, D. A. Roff and D. J. Fairbairn. Oxford, Oxford University Press: 232-238.

Lahti, K. and S. Rytkönen (1996). "Presence of conspecifics, time of day and age affect willow tit food hoarding." Animal Behaviour 52: 631-636.

Lens, L., F. Adriaensen, et al. (1994). "Age-related hoarding strategies in the crested tit Parus cristanus: should the cost of subordination be re-assessed?" Journal of Animal Ecology 63: 749-755.

Lima, S. L. (1986). "Predation risk and unpredictable feeding conditions: determinants of body mass in birds." Ecology 67(2): 377-385. 
Lucas, J. R. and L. R. Walter (1991). "When should chickadees hoard food? Theory and experimental results." Animal Behaviour 41: 579-601.

Lundborg, K. and A. Brodin (2003). "The effect of dominance rank on fat deposition and food hoarding in the willow tit Parus montanus - an experimental test." Ibis 145: 78-82.

Maccarone, A. D. (1987). "Age-class differences in the use of food sources by European starlings." Wilson Bulletin 99(4): 699-704.

May, R. M. (1988). "How many species are there on earth?" Science 247: 1441-1449.

Milius, S. (2004). Where'd I put that? Maybe it takes a bird brain to find the car keys. Science News. 174: 103.

Miskelly, C., R. Empson, et al. (2005). "Forest birds recolonising Wellington." Notornis 52(1): 21-26.

Moncrieff, P. (1931). "Fantails in Nelson province, New Zealand." Emu 31: 111-117.

Moncrieff, P. (1932). "Notes on the South Island robin." Emu 32: 52-58.

Onuki, Y., K. Kato, et al. (2005). "Influences of food type on food-carrying behavior in rats (Rattus norvegicus)." Behavioural Processes 70: 182-185.

Onuki, Y. and J. Makino (2005). "Food-carrying behavior increased under riskapproaching signal in rats (Rattus norvegicus)." Physiology and Behavior $\mathbf{8 4}$ 141-145.

Powlesland, R. G. (1980). "Food storing behaviour of the South Island robin." Mauri Ora 8: 11-20.

Powlesland, R. G. (1981). "The foraging behaviour of the South Island robin." Notornis 28: 89-102.

Powlesland, R. G. (1981b). "Comparison of time-budgets for mainland and Outer Chetwode Island populations of adult male South island robins." New Zealand Journal of Ecology 4: 98-105.

Powlesland, R. G. (1983b). "Breeding and mortality of the South Island robin in Kowhai Bush, Kaikoura." Notornis 30: 265-282.

Pravosudov, V. V. and J. R. Lucas (2000). "The effect of social dominance on fattening and food-caching behaviour in Carolina chickadees, Poecile carolinensis." Animal Behaviour 60: 483-493.

Pravosudov, V. V. (2006). "On seasonality in food-storing behaviour in parids: do we know the whole story?" Animal Behaviour In press. 
Sherry, D. F. (1985). "Food storage by birds and mammals." Advances in the Study of Behavior 15: 153-188.

Smith, C. C. and O. J. Reichman (1984). "The evolution of food-caching by birds and mammals." Annual Review of Ecology and Systematics 15: 329-351.

Soper, M. F. (1976). New Zealand Birds. Christchurch, Whitchoulls Publishers.

Soper, M. F. (1984). Birds of New Zealand. Christchurch, Whitcoulls Publishers.

Stapanian, M. A. and C. C. Smith (1978). "A model for seed scatterhoarding: coevolution of fox squirrels and black walnuts." Ecology 59(5): 884-896.

Stone, E. R. and M. C. Baker (1989). "The effects of conspecifics on food-caching by black-capped chickadees." The Condor 91: 886-890.

Tinbergen, N. (1953). Social behaviour in animals: with special reference to vertebrates. London, Methuen \& Co. Ltd.

Vander Wall, S. B. (1990). Food hoarding in animals. Chicago, The University of Chicago Press.

Wheelwright, N. T. (1986). "The diet of American robins: An analysis of U.S. biological survey records." The Auk 103: 710-725.

Yosef, R. and B. Pinshow (1989). "Cache size in shrikes influences female mate choice and reproductive success." The Auk 106: 418-421. 


\section{CHAPTER TWO}

\section{SEASONALITY OF FOOD USE AND CACHING}

\section{INTRODUCTION}

Seasonal variation in food use strategies are a well-recognised characteristic of many bird species (see Lack 1971). Seasonal changes are dictated both by the social requirements of the individual, and by the prevailing environmental conditions (Gill 1990). For example, the abundance, perceptivity, or vulnerability of prey populations frequently changes seasonally (Gill 1990; Brooke \& Birkhead 1991). In strongly seasonal environments, prey abundances may fluctuate markedly (Roberts 1979). During warm months, individuals feed and breed, thus populations increase. Alternatively, during cool months, many enter torpor or migrate, thus populations decline. Energy requirements also change. Breeding birds require a higher proportion of protein in their diet to facilitate egg production and for juvenile feeding (Koenig \& Mumme 1987; Brooke \& Birkhead 1991). Conversely, in winter, a diet rich in carbohydrates may be more appropriate for generating heat to survive long, cold nights.

Individuals may respond to changing environmental requirements by mediating the frequency of different food use behaviours. In response to seasonal variation, birds often adjust their prey choice, foraging methods, spatial dispersion, propensity to cache food, territoriality, frequency and duration of vocalisations, and degree of sociality (see Gill 1990). Some behavioural traits are only exhibited at certain times of the year and are largely associated with breeding behaviour. 
Examples of these include courtship feeding, nest building, egg laying, incubation, and juvenile feeding. However, other behaviours occur throughout the year. Most bird species do not hibernate, continuing to consume food year-round.

Birds that cache food commonly do so throughout the year, but most show seasonal variation in their caching intensity. For instance, boreal owls (Aegolius acadicus) make their largest caches during egg laying and hatching. However, they may also cache food during winter (Korpimäki 1987). Migratory American Kestrels (Falco sparverius) cache food only during the breeding season (Balgooyen 1976), while non-migratory individuals also cache in the winter (Collopy 1977). Eurasian jays (Garrulus glandularius) cache food mostly in autumn, but will also cache during the breeding season (Pravosudov 1984). In food-caching parids (Paridae), caching intensity is generally highest during autumn (Pravosudov 2006). However, this is largely determined by food supply. Caching intensity in spring may match or exceed autumn in a favourable seed-producing year (Pravosudov 2006).

In general, maximum caching intensity in temperate bird species corresponds with the season of maximum food availability (see Vander Wall 1990). Woodpeckers (Picidae), nutcrackers (Corvidae), pinyon jays (Gymnorhinus cyanocephalus), and other jay species (Corvidae) cache food primarily during autumn and winter when nuts and acorns ripen (Vander Wall 1990). Spring caching of seeds by many Parus spp. is coincident with the opening of Scotch pine (Pinus sylvestris) cones. Similarly, in mammals, Skoczen (1961) found that moles (Talpa europea) cached most intensively during cold weather, as this was when worms, their predominant food source, were inactive and easy prey. Caching of hares (Lepus americanus) by lynx 
(Lynx canadensis) is related to hunting success (Nellis \& Keith 1968). The caching season of flying squirrels (Sciuridae) coincides with ripening of the mast crop (in Vander Wall 1990).

Food-caching behaviour, therefore, is primarily a response to an excess of food (see Smith \& Reichman 1984). Individuals benefit by caching any food that becomes available over and above their immediate direct or indirect energy requirements. This is because excess food that is not used becomes available to competitors, whether con- or heterospecific. Additional food availability encourages competitors to infringe upon their territory and ultimately to reduce their fitness through competition for mates and food. Thus, caching of food removes it from the immediate threat of competition (Cowie et al. 1981; Shettleworth \& Krebs 1982), and, in addition, allows the individual to practice more temporal control over their food use (Anderrson \& Krebs 1978; Vander Wall 1990).

Birds that cache food may be released, to some extent, from seasonal fluctuations in food supply (Vander Wall 1990). However, benefits may vary according to the potential duration of cached supplies. The length of time an item can be cached is often related to the physical nature of the food itself. Birds that store for long periods (e.g. > 2 months), for instance, generally cache seeds. Unlike carrion, seeds have a slow process of decay (Smith \& Reichman 1984). Provided seeds are cached in positions where they are unable to germinate, they can be cached for extended periods without decomposing. Carrion prey, alternatively, tends to decompose rapidly and may attract attention from pilferers because of its relatively strong smell (see Vander Wall 1990). However, some prey abundances may have no 
particular relationship to season. For instance, in insectivores, the unpredictable nature of invertebrate prey encourages food-caching species to make kills and cache prey whenever possible (Vander Wall 1990).

Many previous food-caching studies correlate long-term caching with surviving long-term food scarcity, and short-term caching with overcoming short-term food variability (Lucas \& Walter 1991). Animals that cache during the breeding season could smooth prey fluctuations, thereby improving the facilitation of food to young (Lyons \& Mosher 1982). Caching prior to breeding has been attributed to mate advertisement (Yosef \& Pinshow 2005). However, a unifying characteristic of foodcaching species is that they all cache when they have an excess of food (Smith \& Reichman 1984). As previously discussed, food-caching provides all these animals with an immediate response to the threat of competition. However, despite the apparent utility of this action, the primary determinant of caching is routinely attributed to other causes.

Many studies on caged animals have been criticised for not representing the natural behavioural inclinations of wild animals (Cowie et al. 1981; Pravosudov 2006). For example, Clayton and Dickson (1999) criticise the artificial conditions presented to rats in many studies. However, Clayton and Dickson (1999) could also be criticised for conducting avian experiments in tiny $(91 \times 91 \times 76 \mathrm{~cm})$ enclosures in which subjects are fed dog biscuits. In addition, most studies concerned with caching seasonality have investigated caching behaviour in only part of the year (see Pravosudov 2006). Studies of seasonality in caged birds may be hampered by too many assumptions and too few natural precursors. 
Robins provide an unusual and convenient test case for experiments on food use in wild birds. Throughout the year, birds maintain territories (Powlesland 1980), readily caching excess food. Unlike many north-temperate food-caching birds, limited environmental fluctuations (Hurnard 1978; Moeed \& Fitzgerald 1982; Chan 1994) and relative tameness (Powlesland 1981; Armstrong et al. 2000; Burns \& van Horik 2006) mean that birds can be consistently tracked and observed year-round. Analyses of seasonal patterns in food use are best performed on species that express a wide range of responses to food (Smith \& Reichman 1984). Robins are bold and naïve, undertaking many activities within close proximity of observers (Powlesland 1981; Burns \& van Horik 2006), including courtship, feeding of young, and caching food. In addition, robin food-caching behaviour in field experiments is similar to that observed when handling naturally acquired prey (Alexander et al. 2005).

Previous research has found that robins moderate their food use and caching behaviour seasonally (Powlesland 1980). Powlesland (1980) found that robins cached food throughout the year, but least during breeding, when additional food was fed to young. Birds showed seasonal variation in their diet and foraging techniques corresponding with the abundance and vulnerability of prey species (Powlesland 1981). This study seeks to evaluate, specifically, how robins vary their response to food on a seasonal basis. Results will compare and contrast the use of food by both sexes throughout the year to address two overarching questions: 'Do robins respond differently to food in different seasons?' and 'What is the most likely determinant of food-caching in robins?'. In addition, by comparing behaviour with that of other species, results will aid in the investigation of food use in other birds. 


\section{METHODS}

\section{Study site}

The KWS (Fig. 2) is a $2.5 \mathrm{~km}^{2}$ valley of secondary forest located $2 \mathrm{~km}$ west of the Wellington city centre $\left(41^{\circ} 18^{\prime} \mathrm{S}, 174^{\circ} 44^{\prime} \mathrm{E}\right)$. Its canopy is predominantly a mixture of evergreen native and exotic tree species, with a well-developed native understorey. The KWS is inhabited by about 43 resident and migratory species of native and exotic birds (Raewyn Empson pers. com.). Avian inhabitants are protected from introduced mammalian predators by an exclusionary fence and regular trapping. Climate in the area is characterised by mild, temperate conditions, an average daily temperature of $12.8^{\circ} \mathrm{C}$ and annual rainfall of $1,249 \mathrm{~mm}$ (NIWA 2006). Winter is the wettest time of year, while, in summer, droughts are common (Hurnard 1978). However, in comparison to many temperate climates, there is relatively little variation between summer and winter temperatures (NIWA 2006) (ref. Fig. 3). The austral summer occurs from December, with winter conditions prevailing from June. 


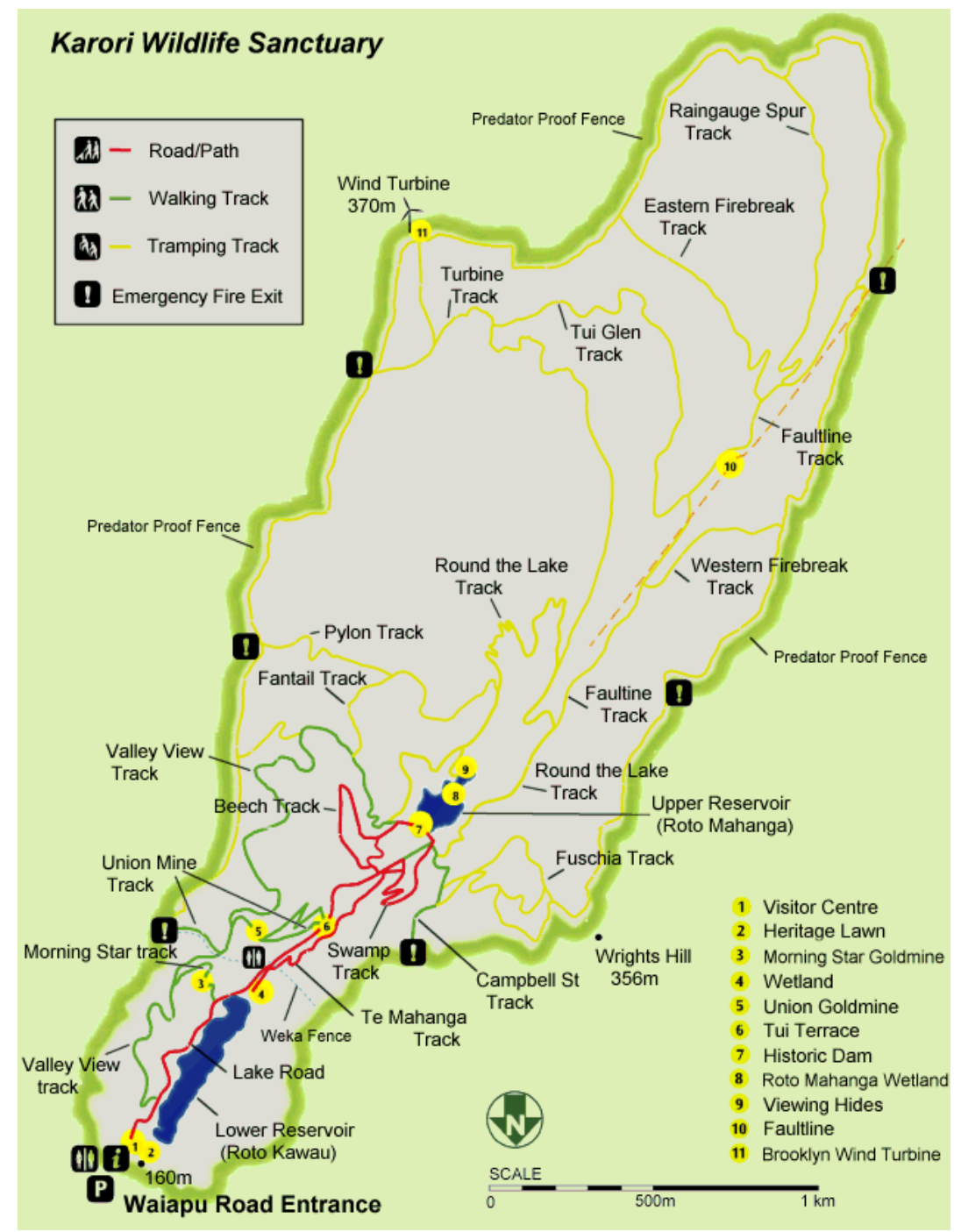

Figure 2: Map of the Karori Wildlife Sanctuary (ㄷ 2000-2006 Karori Wildlife Sanctuary Trust). 


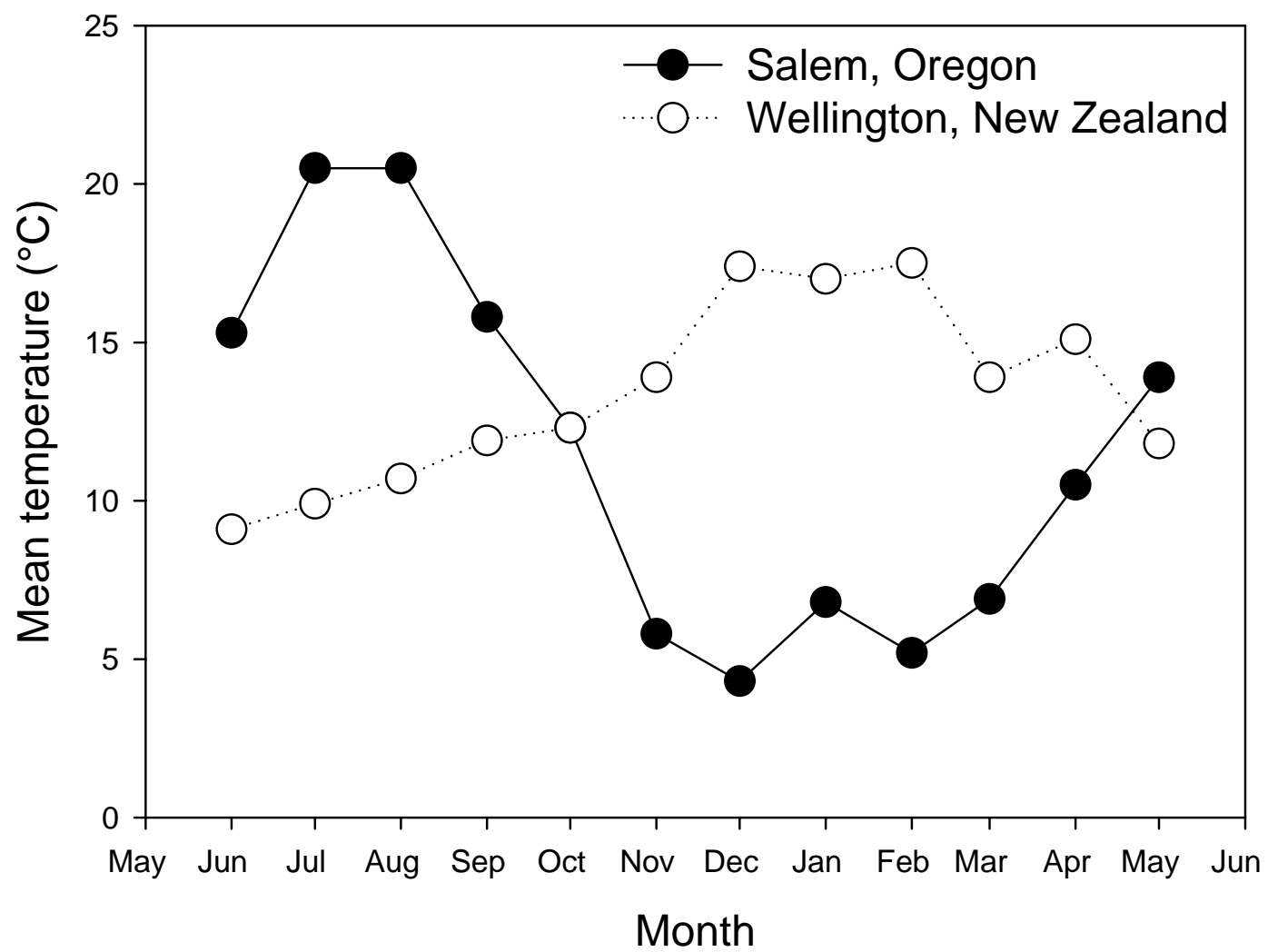

Figure 3: Comparison of monthly temperature variation between the Karori Wildlife Sanctuary, Wellington (New Zealand), and Salem, Oregon (United States of America). Oregon is home to many intensively studied species of north-temperate food-caching birds, including acorn woodpeckers (Melanerpes formicivorus), black-capped chickadees (Parus atricapillus), and Clark's nutcrackers (Nucifraga columbiana) (see Vander Wall 1990) (Data: NIWA 2006; NOAA 2006).

\section{Experimental protocol}

The behaviour of robins was quantified by presenting paired birds with a food resource and observing their responses. The sampling procedure used here closely resembles that used in three contemporary studies (Burns \& Steer 2006, Burns \& van Horik 2006, and van Horik \& Burns 2006). Data were collected to compare seasonal changes in food use behaviour by both sexes. Feeding trials were made in the first 3 hours of daylight during the $22^{\text {nd }}$ to the $28^{\text {th }}$ of each month, from May 2004 to April 2006, except for February 2006. Dawn trials were undertaken as a means of standardising for prior gut contents. This is because robins are not able to begin 
foraging until light levels approach intensities at which they are able to discern prey (see also Powlesland 1981, 1983). Further, many food-caching bird species cache most readily early in the day (Waite \& Grubb 1988), including robins (Powlesland 1980). Trials were not undertaken during heavy rainfall, as birds are inactive during this time. The robin population of the KWS numbered about 200 individuals during observations (Hulls \& Mellor 2005).

Birds were located audibly and/or visually while walking three small forest tracks. These consisted of the 'Round the Lake', 'Faultline' and 'Beech' Tracks (see Fig. 2). Feeding trials would begin when birds were located within $3 \mathrm{~m}$ of the observer. Occasionally, cautious or timid individuals would be enticed to within this distance by a short burst of hand clapping. Loud noises of this nature are associated with the possibility of disturbed prey. Godfrey (2003) attracted robins using a similar method (see also Moncrieff 1932). The prey items offered to robins were mealworm (Tenebrio molitor) larvae, which were each about $2 \mathrm{~cm}$ in length and weighed about 0.10g. Birds were offered $2 \mathrm{~g}$ of mealworms $(n=20.5 \pm$ SE 0.23$)$ which were deposited in a small pile on the ground. The observer would subsequently move to about $5 \mathrm{~m}$ from the site to allow the participants access. The duration of each trial would not exceed $15 \mathrm{~min}$ and was occasionally shorter because of the departure of birds following food acquisition.

Instances in which robins did not use all of the mealworms presented to them were rare. Consequently, the analysis includes only trials in which birds acquired all food items. 'Acquired' mealworms were those that were removed from the point of deposition. Acquired mealworms were used in one of 4 ways, either: 'consumed' if 
swallowed; 'cached' if deposited in the cavity or bark of a tree (or tree fern) branch or trunk; 'courtship fed’ if fed to a mate, or ‘juvenile fed’ if fed to young offspring.

Robins were mostly encountered either alone or in heterosexual pairs, and data were initially collected from birds found with or without their mate. However, locating unaccompanied females proved difficult. While males were often able to temporarily elude or exclude females from a patch of territory, females were seldom able to escape the presence of a mate when extra food was presented. Because of their dominance, males appear to have some measure of independence from their mates. However, females were rarely able to avoid the presence of theirs. The difficulty in finding unaccompanied females is likely associated with the conspicuous presence of the observer and the abundance of food presented. The observer commonly obtains the attention of both sexes in a pair. However, while the male is sometimes able to exclude the female with the threat of physical harm, the female is rarely able to escape the male. Powlesland (1981b) experienced similar problems in attempting to independently survey the behaviour of females (see also Burns \& Steer 2006). In addition, both sexes were difficult to sample independently during breeding, when pairs forage more closely, frequently accompanied by offspring. The combination of an unbalanced sexual and seasonal trial ratio between paired and unaccompanied birds made unaccompanied trials unsuitable for data analysis in this study. However, as robins are generally accompanied by their mate, this condition is the most applicable for analysing natural seasonal variation in food use.

The robin breeding season defined in this study encompasses spring and summer (September to February). The period defined is consistent with the typical 
breeding season of the robin population studied by Armstrong et al. (2000) for seven consecutive years. The non-breeding season includes autumn and winter (March to August). Observations in the field indicated that discussing variation based on these two seasons was the most appropriate way of assessing the effect of season on food use. Individuals do occasionally express breeding behaviour (feeding conspecifics, copulating etc.) outside of these months. Therefore, these categories were not considered appropriate for statistical analyses. However, conceptualising seasonal variation qualitatively with reference to two distinct seasons does have strong biological validity (Gill 1990). Previous researchers (e.g. Powlesland 1981, Armstrong et al. 2000, van Horik \& Burns 2006) have noticed stark differences in behaviour between breeding and non-breeding birds and have thus focussed on one of the two seasons. Therefore, both biologically and conceptually, it is appropriate to focus attention principally on this temporal division.

During the breeding season, juveniles commonly accompanied adults. In this study, 'Adults' were defined as any paired bird, while 'juveniles' were defined as any bird still under the care of its parents. Analysis does not include instances in which more or less than two adult birds were present. Trials involving more than two adult birds were usually disrupted by conspecific territorial interactions. Similarly, data were not included in which any bird arrived after the start of a trial. During each month, birds that had previously been sampled were avoided in later trials for that month. However, some birds were repeatedly sampled in the same month. To avoid pseudo-replication, multiple trials of the same individual within-month were averaged so no bird was represented more than once a month in analyses. Trials of unbanded birds were treated independently. 
When presented with an abundance of mealworms, robins frequently used food slower than would appear necessary. When acquiring mealworms, birds would take each mealworm in their beak individually, either consuming them or transporting them to another location. Often birds would take numerous items in their beak before transportation. A robin can carry up to about 10 mealworms in its bill at once and will take more than one trip to use the $2 \mathrm{~g}$. However, occasionally a bird would attempt to simultaneously monopolise and devour every mealworm at once (see also Moncrieff 1932; Soper 1976). A time consuming activity ensues in which mealworms are routinely packed into the beak until its capacity is exceeded and then wholly dumped back to the ground. A bird would fill and then vacate its beak in this way more than 10 times before it began to make effective use of the food source by handling it in repeated trips. The behaviour would continue for between about $30 \mathrm{sec}$ to $5 \mathrm{~min}$. This combination of prolonged handling time and repeated dropping and re-acquiring will be called here 'indecision'. The presence of indecision in any bird was noted.

Aggressive behaviour was frequently observed both during and between feeding trials. Territorial interactions between neighbouring pairs were an especially prominent and widespread behaviour. The behaviours elicited during these interactions were not uniform, ranging from loud singing and aggressive chases to flashing the frontal spot (see Flack 1976) or, rarely, complete motionlessness. Feeding trials during these times were generally impossible as birds would show no interest in food. During trials, aggression was also observed between mates (see also Burns \& Steer 2006), and between adults and juveniles. Intra-pair aggression was always instigated by the male, usually in response to competition for food. Both sexes would 
also show occasional aggression towards juveniles in the breeding season. The amount of aggression exhibited by birds was measured by recording instances in which one bird physically displaced another (see also de Kort et al. 2006). 'Displacements' were characterised by a rapid direct flight of one bird in the direction of another. The movement would induce the formerly stationary victim to fly to another perch while the aggressor would usurp their position. Displacements invariably drove the respondent further from the food source. Additional displacements would often follow until the aggressor was satisfied with the victim's new position relative to the food. The number of displacements exhibited by each bird was recorded.

Both banded and unbanded birds were sampled. Banded individuals were each marked with a unique combination of metal and colour bands (see Armstrong et al. 2000). These indicate either the year of fledging, or, in the case of birds that were transferred to the sanctuary, the date of introduction. Sexes of banded birds were identified by recourse to banding records, and further corroborated by observations in the field. Unbanded birds could be sexed by noting the sex of their partner and observing their behaviour in the field. Trials involving birds of the same sex were easy to distinguish as they usually ended in fierce fighting.

In total, 113 feeding trials were conducted on 45 banded birds and an unknown number of unbanded birds. Trials were only undertaken on pairs in which one of the birds was banded. In 24 trials, one bird was unbanded. However, the sex of the unbanded bird could be inferred from behavioural interactions. The first year's data consists of 68 trials on 39 banded birds (16 banded males and 23 banded females), 
while the second included 45 trials on 22 banded birds (13 banded males and 9 banded females). The aggregate number of trials per month ranged from 2 to 12 ( $\bar{x}=$ 4.9). Most banded birds were repeatedly sampled. Specifically, between 1 to 15 times $(\bar{x}=4.3)$, including 17 individuals (10 banded males and 7 banded females) that changed partners during the two-year investigation. The number of trials conducted varied monthly, mainly because of adverse weather precluding trials. However, about the same number of trials were conducted in the breeding and non-breeding seasons (breeding = 57; non-breeding $=56$ )

\section{Data analysis}

To test for seasonal variation in food use the number of mealworms acquired, consumed, cached, fed to a mate, and fed to juvenile/s were recorded for each bird in each feeding trial. For some analyses, the total number fed to conspecifics for each bird was also calculated (number fed to mate + number fed to juvenile(s)). As male and female birds acquired different numbers of prey, proportions were also calculated for each bird by dividing the number of mealworms devoted to any activity by the total number of mealworms acquired by that bird. The mean proportion of mealworms devoted to each food use, by individual, was then averaged according to sex for each month. Thus, the mean proportion of food devoted to each food use by sex is calculated for each month. In addition to recording the number of items cached, the number of cache sites and caching flights made by each bird was noted. As male and female birds cached different numbers of prey, proportions were calculated for each bird by dividing the number of cache flights (and sites) by the total number of mealworms cached by that bird. 
Statistical analyses were carried out in SPSS ${ }^{\circledR} 12.0$ (SPSS 2003). To test for seasonal variation in food use, a Linear Mixed Model (LMM) for count data was used (see van Horik \& Burns 2006, for a similar application). While the general linear model is used to quantify the relationship between several independent or predictor variables and a dependent variable, the LMM extends this approach to incorporate repeated measures and random effects. The LMM test is appropriate for situations in which repeated measures are not consistently made on all subjects (in van Horik \& Burns 2006). The model used here incorporated 'sex' and 'month' as fixed factors, taking 'bird' and 'year' as random variables. As many banded birds were repeatedly sampled, 'month’ was specified as a repeated measure.

To account for variation in the number of mealworms acquired or cached per trial 'number acquired by bird ', 'number acquired by pair', 'number cached by bird, or 'number cached by pair' was used as a covariate of the dependent variable tested. Covariates were assigned by recognising which factor could most likely explain variation independently of the dependent variable. The number acquired by pair was used as a covariate in analyses of the number acquired by bird and the time to handle worms by pair. The number acquired by bird was used as a covariate for the number consumed, number fed to conspecifics (mates or juveniles), and the number cached. The number cached by bird was used as a covariate for the number of cache sites and the number of caching flights. Finally, the number cached by pair was used as a covariate for the number of cache retrievals. As the effect of covariates is incorporated into the LMM and not specifically relevant to this analysis, their associated statistics are not reported in the results. 
Birds were timed for how long it took the pair to use $2 \mathrm{~g}$ of mealworms. Seasonal variation in the time taken to use mealworms was also assessed using a LMM. To calculate the mean time to use each prey item, the time taken to handle the bundle was divided by the number of mealworms of which it consisted. The number of mealworms transported to conspecifics per feeding event was also calculated.

The expression of indecision and the frequency of aggressive displacements during a trial were noted as these noticeably influenced the speed and nature of food use. The proportion of birds expressing both behaviours was calculated for each month. Seasonal variation in the frequency of displacements was assessed using a LMM. The duration of indecisive behaviour was not quantified so data for this variable consisted solely of records of presence or absence. Consequently, seasonal variation in the expression of indecision was analysed using a chi-square test.

Robins generally consume all prey items below about $1 \mathrm{~cm}$ in length immediately (see also Powlesland 1981), and only larger prey are cached. To ensure that each item was considered as a possible candidate for caching by the birds, all items used in trials were at least $2 \mathrm{~cm}$ in length. However, the mealworms' individual weights fluctuated according to their age. Therefore, the number of mealworms in a $2 \mathrm{~g}$ bundle was not uniform. In addition, male birds were found to acquire a larger number of mealworms than females. Proportions may sometimes inflate variation between subjects, because some food use behaviours have finite limits while others are potentially unlimited. For example, a robin can only consume food until the capacity of its stomach is reached. The number of worms cached, on the other hand, is limited only by the number and capacity of potential cache sites. Therefore, although 
both sexes may consume a small proportion of food before caching, the sex that acquires the most mealworms will be found to cache a higher proportion of food (assuming here that birds can only consume or cache). This is because every additional worm that is acquired, beyond the point of satiation, will increase the proportion of food cached for that bird. Thus, unrepresentative proportions may be an artefact of the experimental manipulation. To standardise for the discrepancy in the number acquired, both between trials and sexes, data were transformed. Firstly, the number acquired, consumed, courtship fed, juvenile fed, or cached by each bird was logged to remove the effect of outliers and to improve the normality of the data. Secondly, linear regression was used to find the standardised residual of the dependent variable. Linear regression removes the effect of the number acquired or cached (depending on the variable) so that the dependent variable can be directly compared between separate trials and sexes. Standardised residuals were used to present findings in which the dependent variable was confounded by the number acquired or cached in both sexes and seasons.

Results are presented graphically using SigmaPlot ${ }^{\circledR} 8.02$ (SPSS 2002) in two charts. An error plot shows the variation in behaviour (e.g., number consumed) exhibited by season (breeding or non-breeding), and sex, when statistically corrected for the number acquired or cached (depending on the variable). In addition, a line graph shows either the proportion, or mean number, of mealworms (uncorrected for number acquired or cached) devoted to each activity by season (month) and sex. The combination of error plot and line graph is intended to help the reader to delineate seasonal and intersexual patterns (error plot) while still observing the broad scope of the data (line graph). 


\section{RESULTS}

\section{Food acquisition}

Males dominated the food resource year-round, acquiring 3.3 times more mealworms than females $($ male $=15.7 \pm 0.61 \mathrm{SE}$; female $=4.7 \pm 0.48 \mathrm{SE})\left(F_{1,78}=457.3, P<\right.$ 0.001) (Fig. 4). Female food acquisition generally consisted of rapid grabs during the short periods in which the male was distracted caching food or feeding juveniles. The proportion of food acquired by male and female birds did not vary seasonally $\left(F_{11,19}=\right.$ 0.036, $P=0.99$ ) (Fig. 4), however, the time taken for a pair to use $2 \mathrm{~g}$ of mealworms did $\left(F_{11,18}=6.6, P<0.001\right)$. Birds used food faster in the breeding season of year two $(\bar{x}=4.4 \mathrm{~min} \pm 0.42)$, than in the breeding season of year one $(\bar{x}=6.2 \mathrm{~min} \pm 0.37)$ $\left(F_{1,51}=9.7, P<0.005\right)$ (Fig. 5). The mean time to handle each mealworm was 29sec ( $\pm 0.01 \mathrm{SE}$ ). Mealworms were sometimes immobilised by being crushed between the bird's mandibles, or vigorously shaken and pounded to the ground. However, when cached, many items were still alive and unharmed.

\section{Indecision and aggression}

Indecision was expressed only by male robins. The proportion of males expressing the behaviour varied seasonally $\left(\chi_{26}^{2}=68.7, P<0.001\right)$. A higher proportion of males expressed the behaviour during the breeding (mean proportion $=0.53$ ) than the nonbreeding season $($ mean proportion $=0.10)($ Fig. 6$)$.

The frequency of male aggressive displacements varied seasonally $\left(F_{11,26}=\right.$ 17.7, $P<0.001$ ). A lower proportion of males were aggressive while breeding (mean proportion $=0.21)$ than during non-breeding (mean proportion $=0.71)($ Fig. 6). Males 
were aggressive towards females year-round, and also towards juveniles towards the end of the breeding season. Female-made displacements were rare $(n=3)$ and all directed at juveniles.

Robins were seen aggressively interacting with a large number of other bird species, including chaffinches (Fringilla coelebs), tui (Prosthemadera novaseelandiae), silvereyes (Zosterops lateralis), blackbirds (Turdus merula), fantails (Rhipidura fuliginosa), hihi (Notiomystis cincta), saddlebacks (Philesturnus carunculatus) and bellbirds (Anthornis melanura). One instance of interspecific cache pilferage was observed in April 2005. A male hihi pilfered a mealworm from a robin’s cache site. Further, on two occasions, a blackbird displaced a robin as it was using food on the ground and began consuming the experimental food. In both instances, food had already been cached by a robin in a nearby site. Once the blackbird had finished consuming the mealworms on the ground, it continued foraging as normal. On neither occasion did the blackbird pilfer cached food.

\section{Consumption}

A small portion of the food source was generally consumed before any other food handling activity. Mealworms were mostly swallowed after little or no mastication. The proportion of food consumed varied seasonally $\left(F_{11,12}=46.6, P<0.001\right)$ and by $\operatorname{sex}\left(F_{1,9}=5.1, P=0.049\right)$. There was an interaction between sex and season $\left(F_{10,15}=\right.$ 9.3, $P<0.001$ ). Robins ate a higher proportion of food during the non-breeding season than the breeding season (Fig. 7). Both sexes ate the same proportion during the non-breeding season. However, females ate a greater proportion than males in the breeding season. No systematic observations were made concerning the incidental 
acquisition of other (non-mealworm) prey items during feeding trials, or the methods used to procure them. However, robins fed on a range of other prey, including spiders, katydids, caterpillars, isopods, moths, centipedes, weta, cicadas, Peripatus spp., and earthworms. One instance of frugivory was observed in late-February 2005 when a pair of robins repeatedly fed on mahoe (Melicytus ramiflorus) berries.

\section{Food sharing}

Mealworms were frequently fed to mates and juveniles (conspecifics) in the breeding season. The number of mealworms fed to conspecifics varied seasonally $\left(F_{11,19}=75.7\right.$, $P<0.001)$, and also by the sex of the feeder $\left(F_{1,78}=10.5, P<0.005\right)$. There was an interaction between sex and season $\left(F_{10,15}=58.5, P<0.001\right)$.

Courtship feeding was undertaken solely by the male. Females were never found to reciprocate. Feeding was prompted by the female, who would adopt a begging posture while emitting a continuous whining call. The feeding process was generally hasty with $40 \%$ of mealworms being dropped during transport from the point of acquisition to the recipient. Males would commonly attempt to feed mates more mealworms than could adequately fit in the recipient's bill. Dropped mealworms were recollected and again transported to the female. Mating was occasionally seen after feeding. Courtship feeding was observed in 26 feeding trials. Most feeding occurred during the specified breeding season - September to February (Fig. 8). However, two notable feeding events occurred slightly earlier in late-August 2005. October was the month with the highest mean proportion fed to a mate (mean proportion $=0.27$ ). Taking only the trials in which mealworms were fed to a mate, the mean number of mealworms transported was $8.6( \pm 1.37 \mathrm{SE}, n=18)$. 
Juvenile (offspring) feeding was shared by both sexes, solely during the breeding season. Males fed a higher proportion of food to juveniles than females did (Fig. 9). In addition, as males acquired a greater proportion of food than females (Fig. 4), males fed more mealworms to juveniles per trial (male $=2.6 \pm 0.56 \mathrm{SE}$; female $=$ $0.4 \pm 0.19$ SE). December was the month with the highest proportion fed to juveniles for both males (mean proportion $=0.72$ ) and females (mean proportion $=0.44$ ) Juvenile feeding closely resembled courtship feeding in that it was prompted by the begging posture and continuous whining call of the potential recipient.

In males, a high proportion of food (mean proportion $=0.20$ ) was dropped during transport from the point of acquisition to the recipient (whether mate or juvenile). However, females dropped a lower proportion (mean proportion $=0.09$ ) of food during transport to juveniles. Dropped mealworms were recollected and again transported to the juvenile. Considering only trials in which adults transported food to juveniles, males transported a higher mean number of mealworms $(\bar{x}=11.0 \pm 1.04$ SE, $n=21$ ), than females ( $\bar{x}=5.0 \pm 1.23 \mathrm{SE}, n=9$ ). Nestlings and fledglings were fed by both sexes. When two fledglings were present, sexes would commonly divide care; each bird feeding only one fledgling. As males acquired a greater mean proportion of mealworms (Fig. 4), the fledgling fed by the male would commonly obtain a greater number of mealworms than that of the female.

\section{Caching}

Robins cached food year-round. The proportion of food cached varied according to sex $\left(F_{1,29}=8.9, P=0.006\right)$ and season $\left(F_{11,13}=13.8, P<0.001\right)$. There was an 
interaction between sex and season $\left(F_{11,13}=15.1, P<0.001\right)$. Male birds cached a greater proportion of food in the non-breeding than the breeding season (Fig. 10). Females cached a higher proportion of food than males in the breeding season, but a lower proportion in the non-breeding season. However, the proportion cached by females did not vary between the breeding and non-breeding season (Fig. 10). Males cached the highest proportion of mealworms in April (mean proportion $=0.74)$ and the lowest proportion in October (mean proportion $=0.09$ ). Females, alternatively, cached the highest proportion in July (mean proportion $=0.51$ ) and the lowest in January (mean proportion $=0.13)$.

During trials, robins often re-used cache sites. Birds often made repeated trips to the same cache site both within trial (see also Alexander et al. 2005), and between trials. Often, birds repeatedly used the same cache site in separate months, however, sexes never cached in the same sites within trial. Female birds appeared to cache further from the point of acquisition than males, although this was not quantified. In most instances, birds immediately left their cache site following deposition.

\section{$\underline{\text { Number of cache sites }}$}

Individual birds made between 1 to 8 cache sites per trial. The number of cache sites made by birds varied by season $\left(F_{11,18}=7.4, P<0.001\right)$ and by sex $\left(F_{1,55}=5.0, P=\right.$ 0.025). Both sexes made more cache sites per trial in the non-breeding season (male = $2.4 \pm 0.19 \mathrm{SE}$; female $=1.0 \pm 0.21 \mathrm{SE})$ than the breeding season $($ male $=1.0 \pm 0.16$ $\mathrm{SE}$; female $=0.6 \pm 0.12 \mathrm{SE}$ ). After controlling for the number cached, females made more cache sites than males in both seasons (Fig. 11). 
$\underline{\text { Number of caching flights }}$

Cached food was transported either singly or in small bundles. The maximum number of mealworms transported in one flight was 10. The number of caching flights varied seasonally $\left(F_{11,10}=6.8, P<0.001\right)$, but not between sexes $\left(F_{1,11}=0.13, P=0.72\right)$. However, there was an interaction between season and $\operatorname{sex}\left(F_{11,11}=3.4, P=0.024\right)$. When controlling for the number cached, females made a greater number of caching flights than males in the breeding season, but the same number in the non-breeding season (Fig. 12). Males transported a mean 2.8 ( $\pm 0.25 \mathrm{SE}$ ) mealworms per caching flight. Females, alternatively, transported a mean 1.4 ( $\pm 0.16 \mathrm{SE})$ mealworms per caching flight. Both sexes made a greater number of caching flights per trial during the non-breeding season (male $=5.1 \pm 0.48 \mathrm{SE}$; female $=1.7 \pm 0.44 \mathrm{SE}$ ), than the breeding season $($ male $=1.9 \pm 0.40 \mathrm{SE}$; female $=0.9 \pm 0.20 \mathrm{SE})$.

\section{Retrieval}

Cache retrievals were encountered infrequently, mostly in the non-breeding season. The total number of retrievals varied seasonally $\left(F_{11,10}=4.4, P=0.017\right)$, but not by sex $\left(F_{1,13}=0.05, P=0.81\right)$. More retrievals occurred during the non-breeding season than the breeding season (Fig. 13). Males retrieved food from their own caches in 16 instances (12 in the non-breeding season), while females did so in 9 (6 in the nonbreeding season). Conversely, retrievals from a mate's cache were seen on 3 occasions in males (all in the non-breeding season) and 15 in females (13 in the nonbreeding season). 
Mean number of prey acquired ( \pm se)
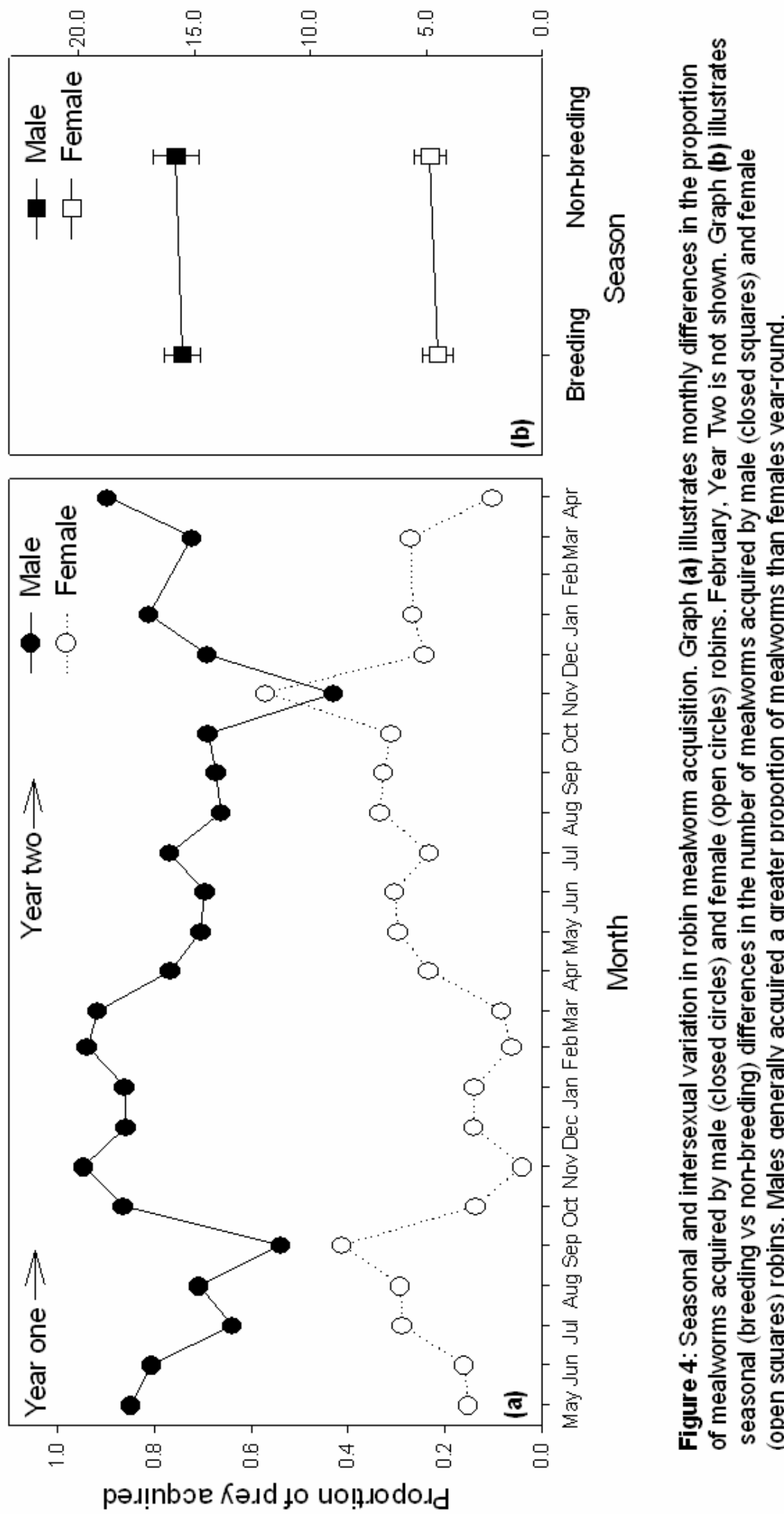

을 은 要

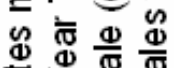

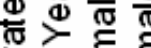

离

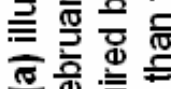

뜨늘 흘

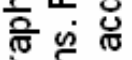

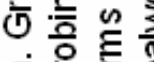

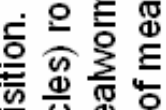

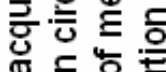

틍ㅎㅇㅎㅎㅇ응

웧응

栗远

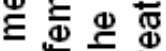

등 ․ㅡㅇ

은 후엄

으웡

은흔 헣헝

는 등

을 은 응 힝

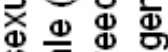

혼

츠응 혼

동 v

뜰 응

웧

蛋

$\Phi$ 흐

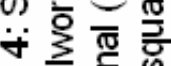

产焉

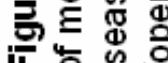


Mean time for pair to use prey (controlling

for number acquired by pair using standardised residuals \pm se)
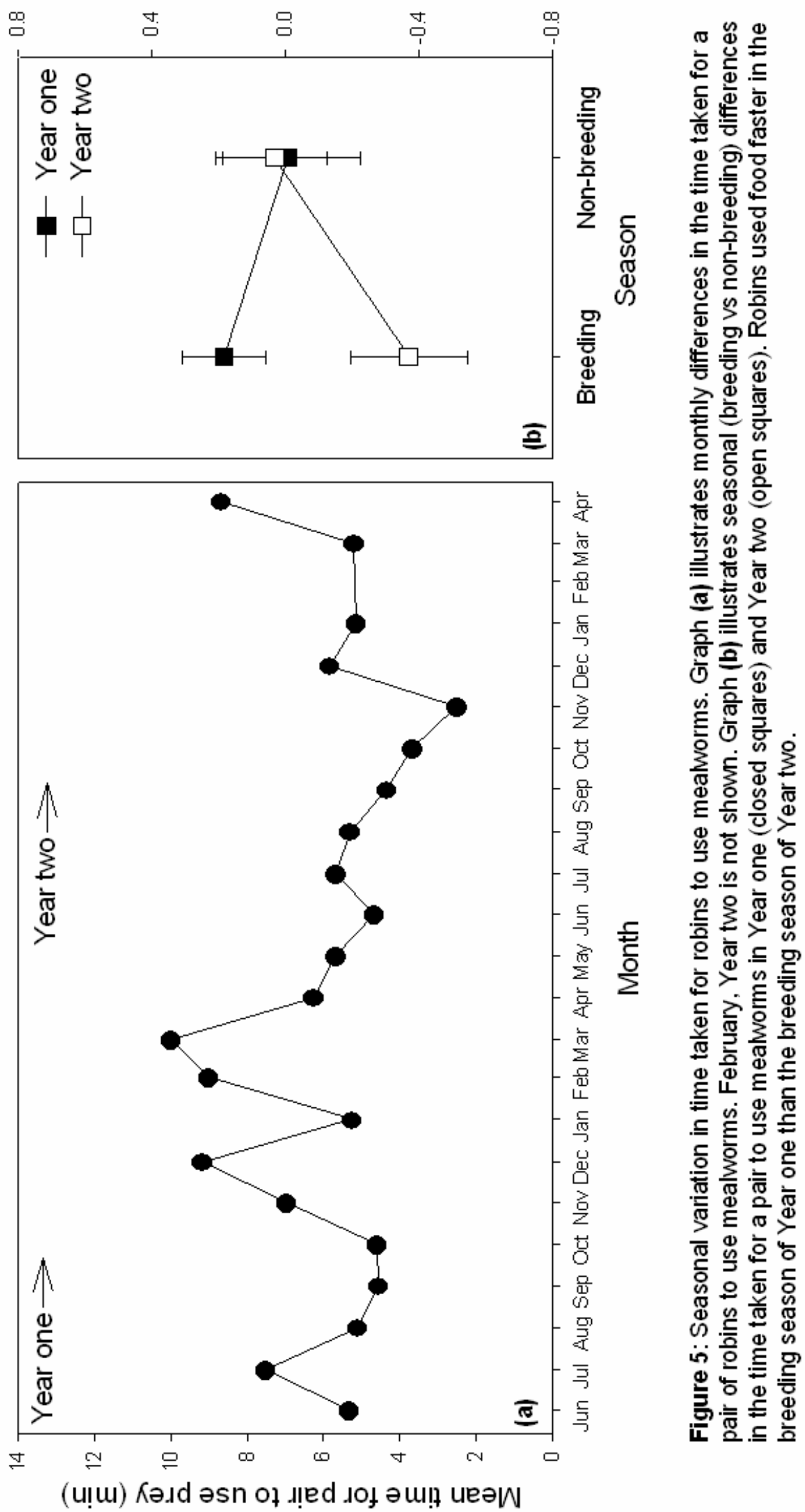

(u!u) Kə.ld əsn of .l!ed .lof әu!̣ ueəW 
Mean proportion of males displaying behaviour ( \pm se)
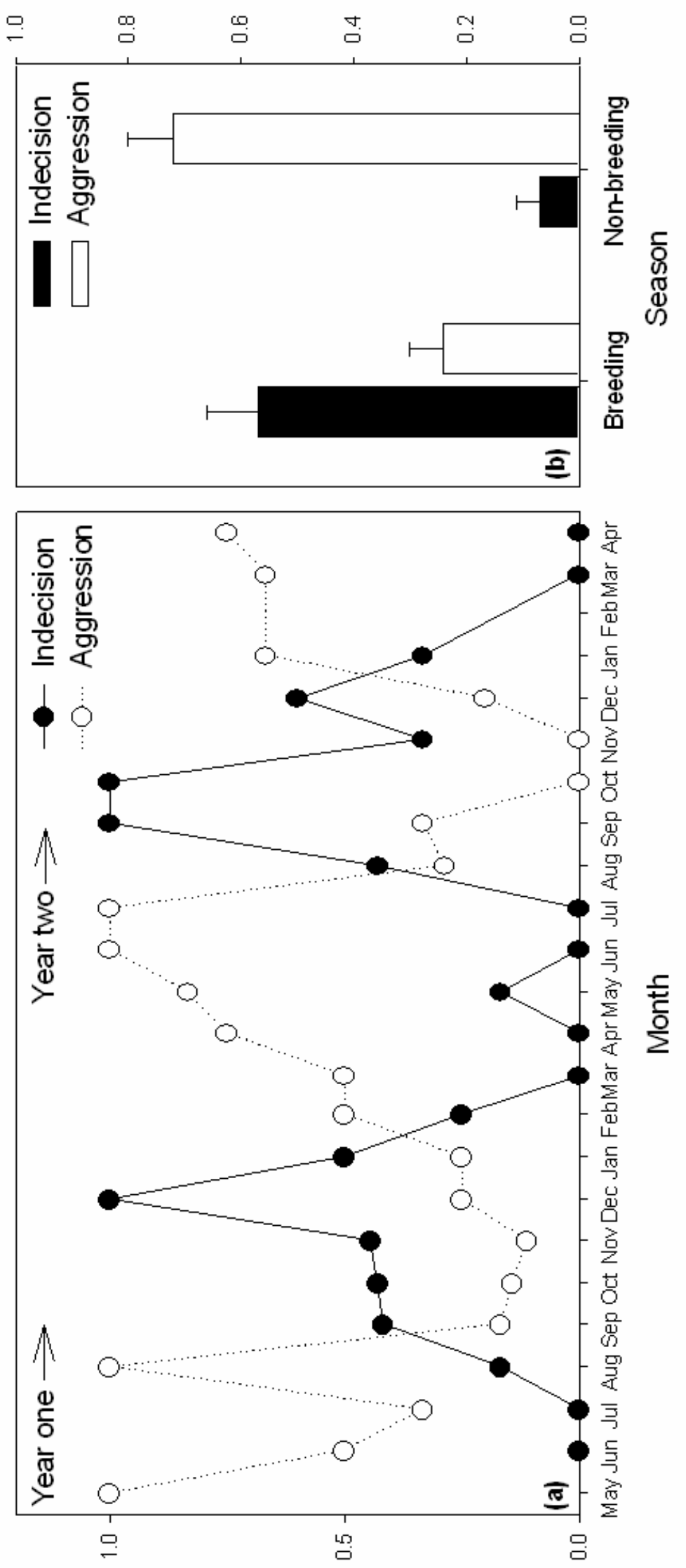

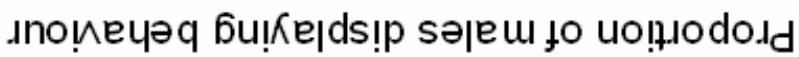

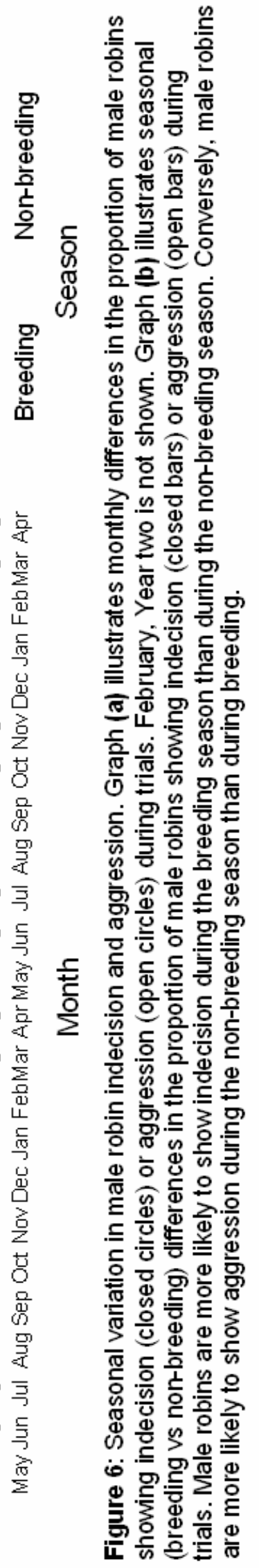


Mean number of prey consumed by bird (controlling for number acquired by bird using standardised residuals \pm se)
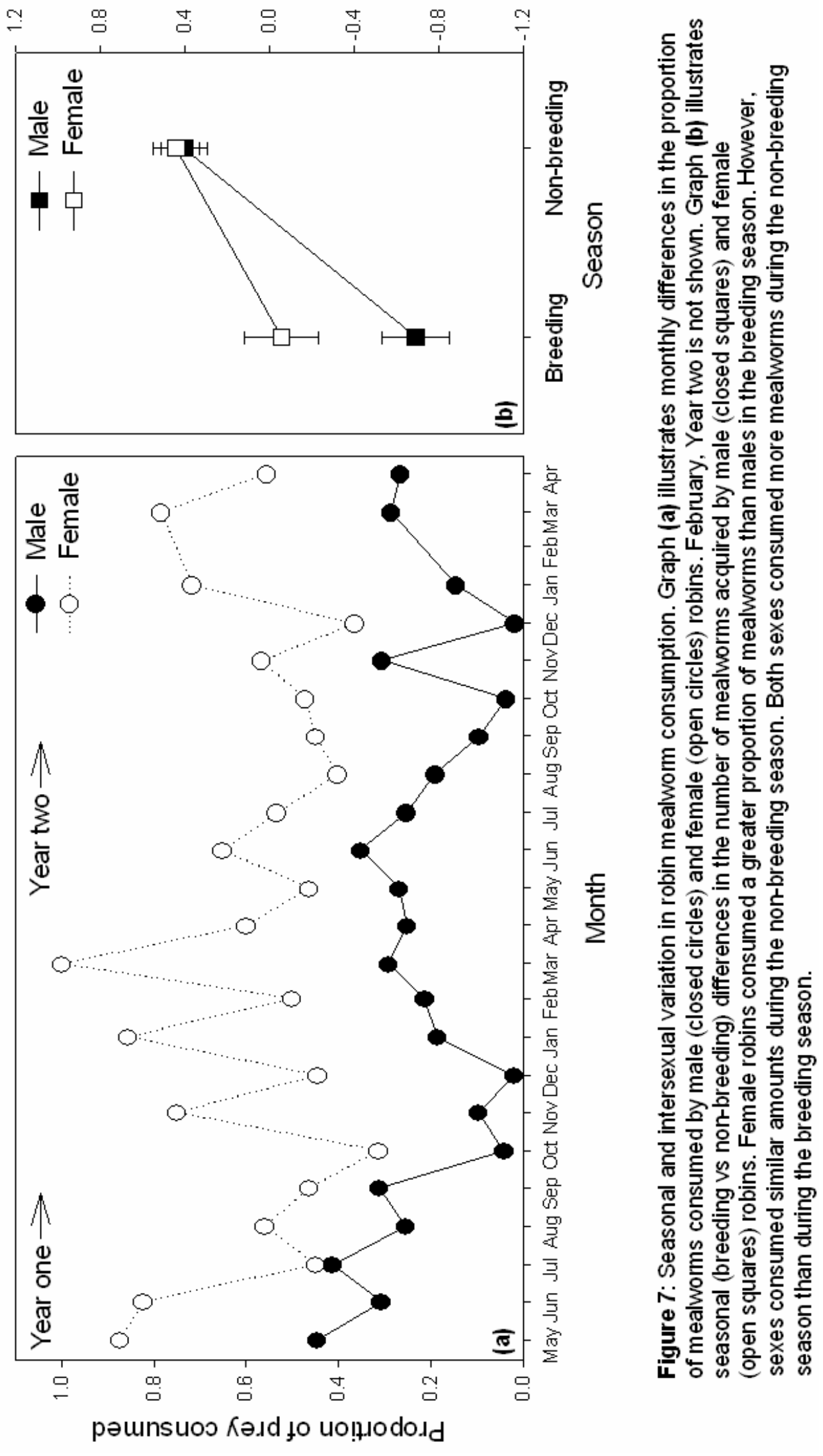
Mean number of prey fed to a mate divided by number acquired by bird ( \pm se)
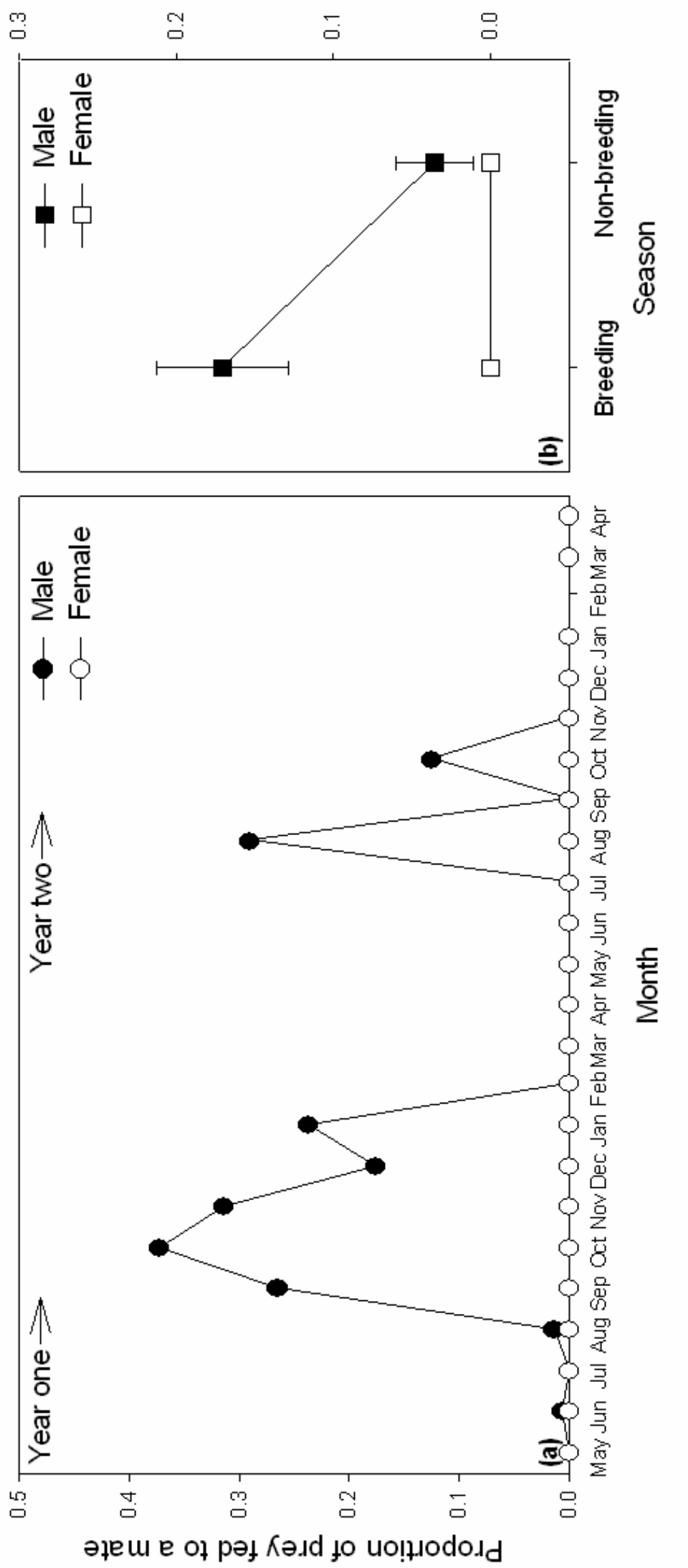

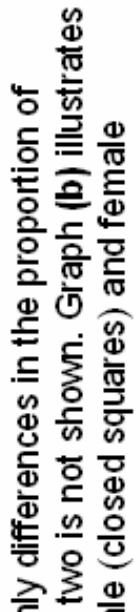

좋

옳

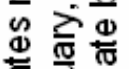

돈

뜽

는

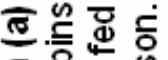

등은 용

可合

要

믄

政

응 훙

을

क⿹ 口力

䛌 恋

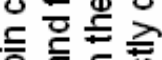

응 들

要要

$\subseteq$ o.

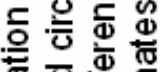

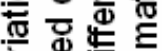

(5)

긍

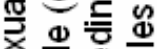

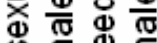

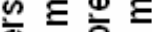

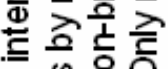

등응

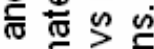

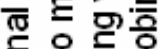

훙은 흔

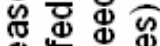

ஸे क⿺⿻一⿰冫⿰亅⿱丿丶丶⿱⿰㇒一乂

os

ब

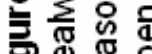

눈 $\stackrel{\infty}{\infty}$

әfeuा e of pəf Кә.ld fo uo!̣ıodold 
Mean number of prey fed to offspring divided by number acquired by bird ( \pm se)
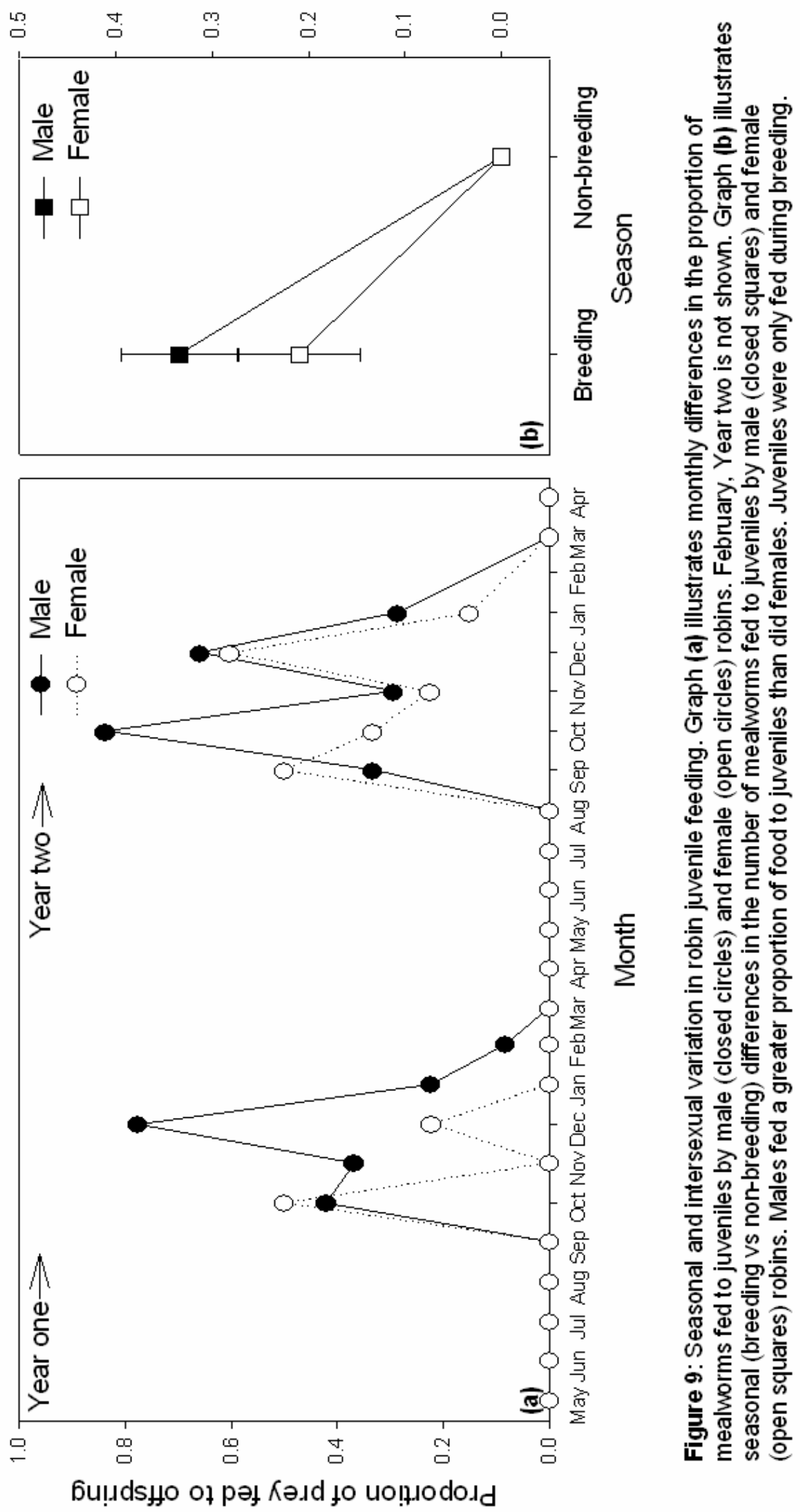

는 
Mean number of prey cached (controlling for number acquired by bird using standardised residuals \pm se)
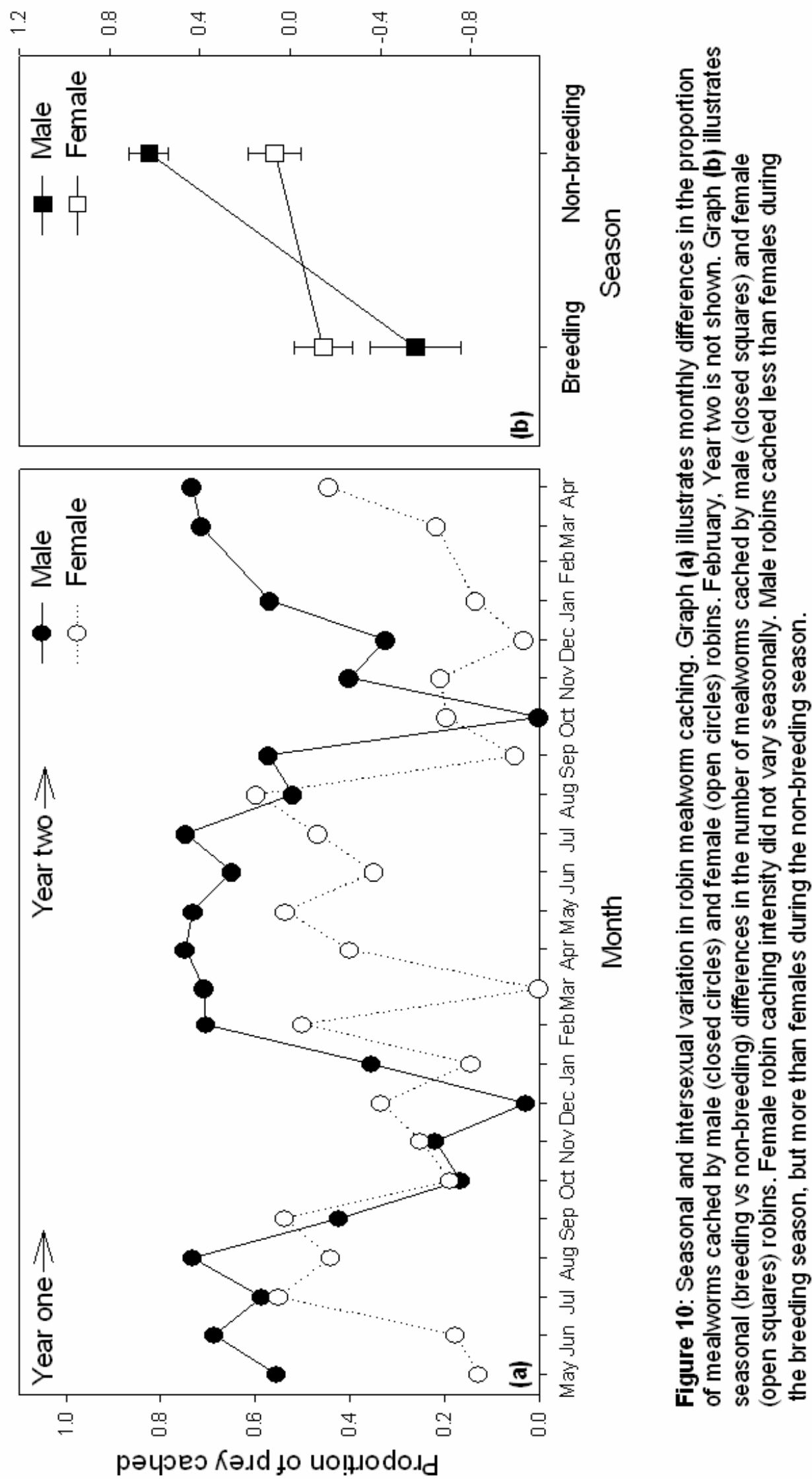


\section{Mean number of cache sites (controlling \\ for number cached by bird using \\ standardised residuals \pm se)}
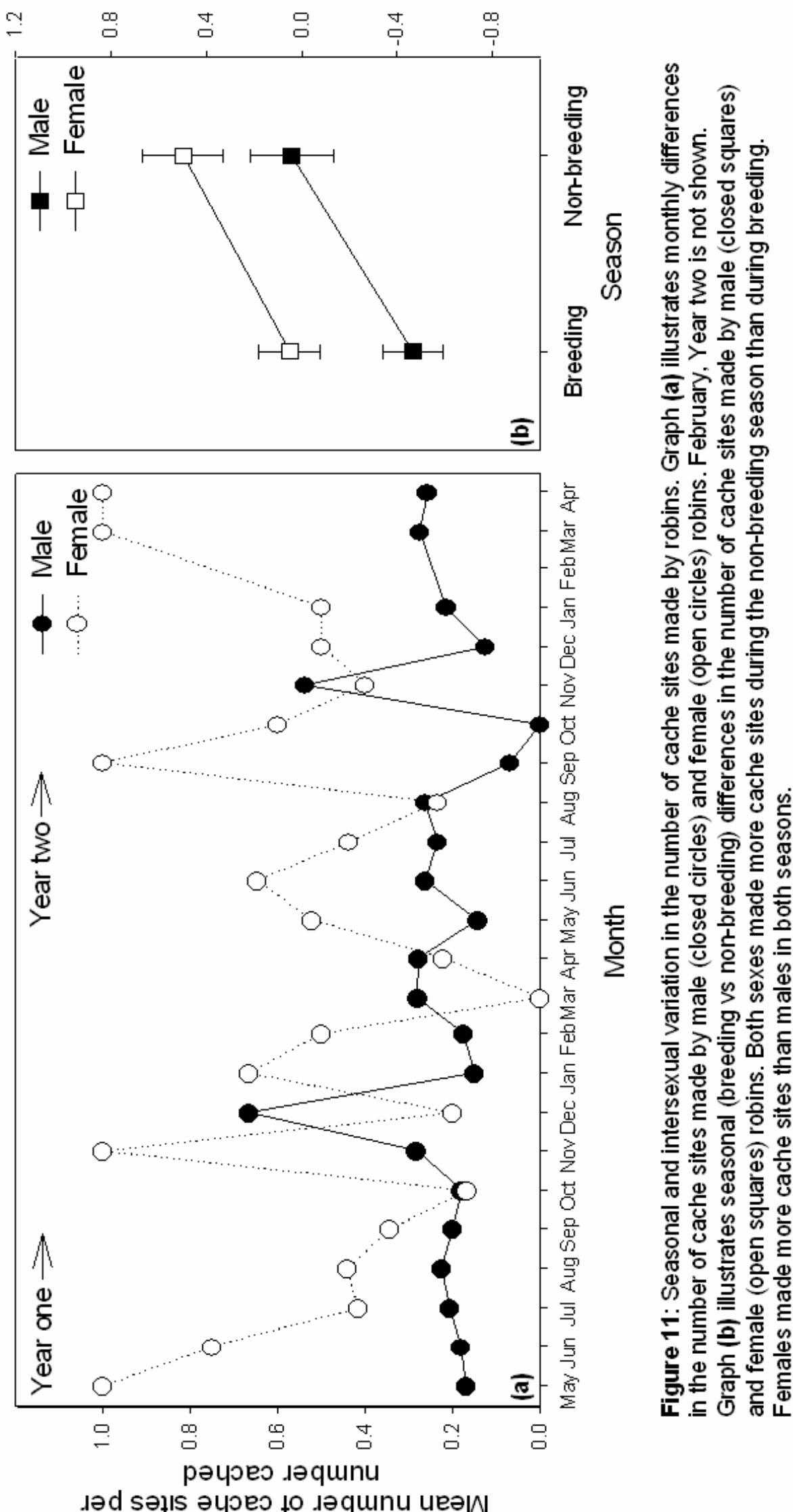

ㄴㄴ

米它

응은 언 훈

त象

응 늘

要完

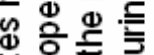

क

里

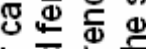

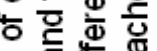

可些 它

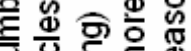

는

$\Phi$ 娄

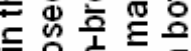

든 응 s.

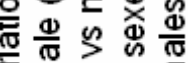

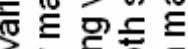

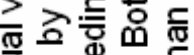

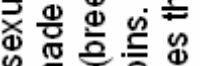

$\stackrel{\mathbb{0}}{\Xi}$ 응

吉悉

的象

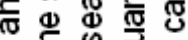

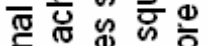

需

(⿻)

心 क

드ㄹㅡㅡ을

(1)

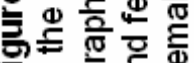

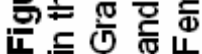

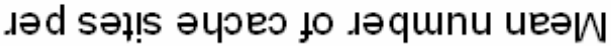


Mean number of cache flights (controlling for number cached by bird using standardised residuals \pm se)
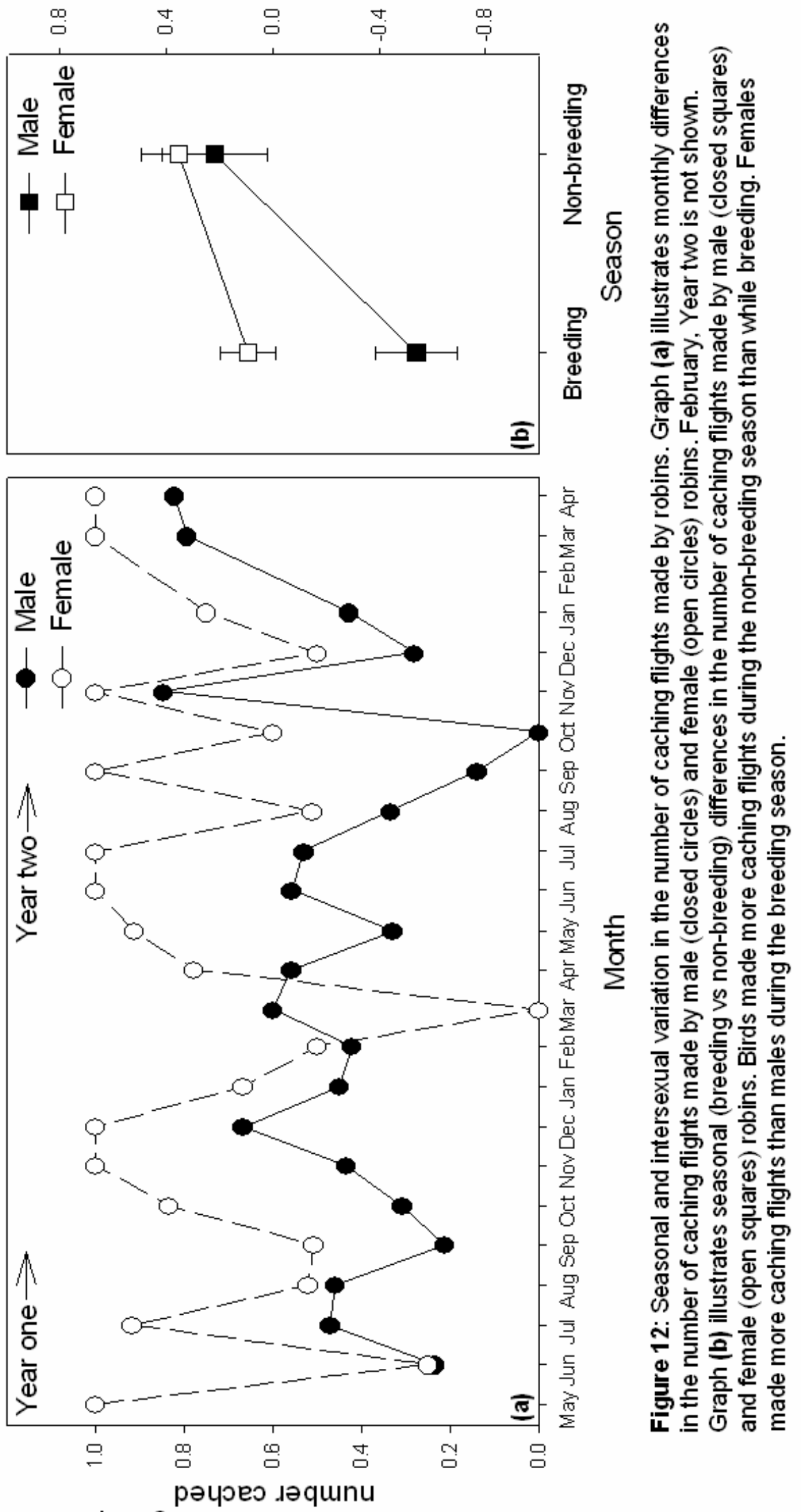

.ləd słц6! ! әцәео to .ləqunu ueəw 
Mean number of cache retrievals (controlling for number cached by pair using standardised residuals \pm se)
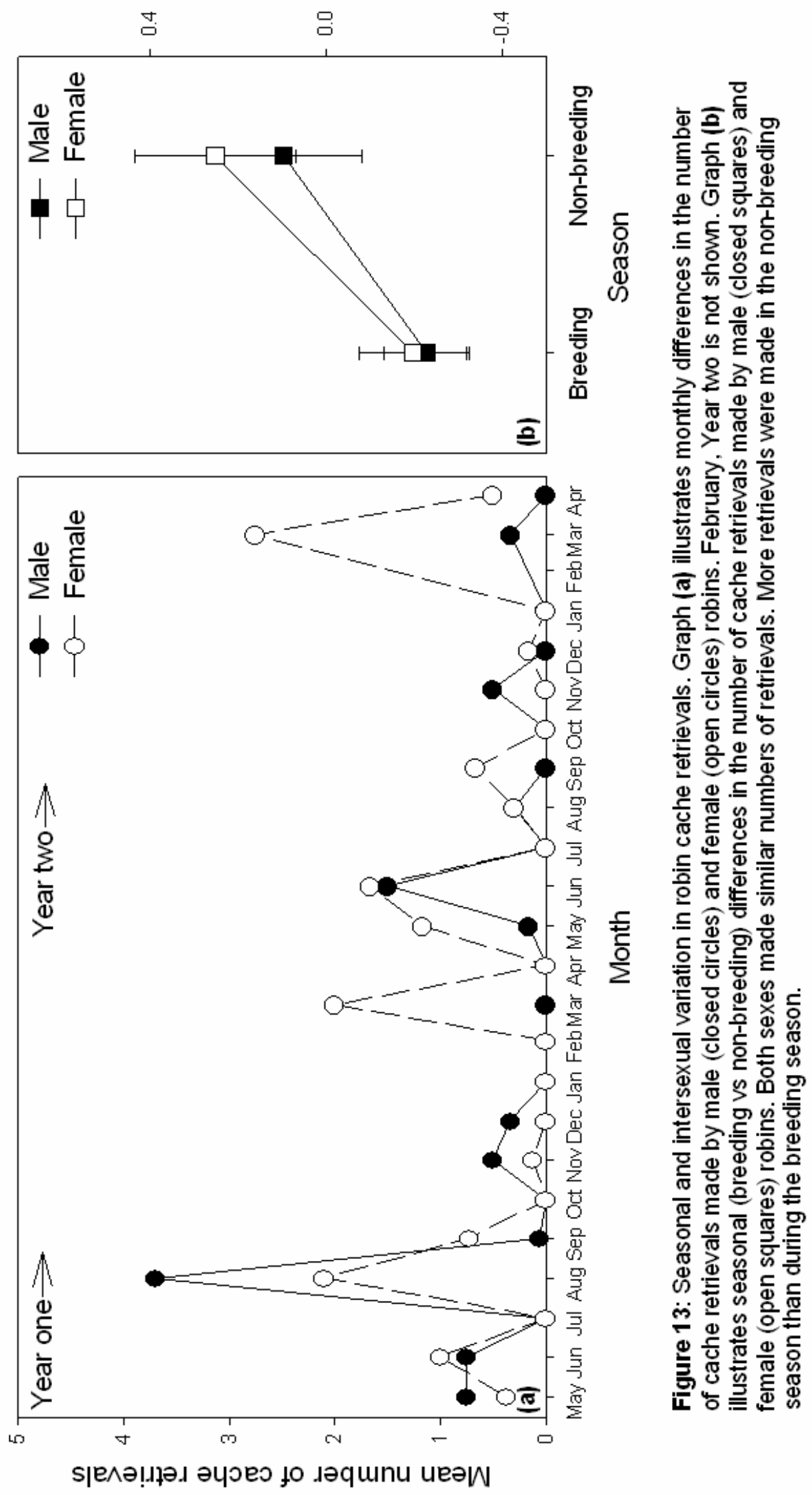


\section{DISCUSSION}

\section{Food acquisition}

Throughout the year, male robins monopolised experimental food sources and consistently acquired more mealworms than females. In a similar experiment, Alexander et al. (2005) found that males acquired about three times as many mealworms as females in winter. Results reported here showed that even during the breeding season, when many items were subsequently fed to mates, males still maintained priority access to food. Although sexes are similar in size (Higgins \& Peter 2002), dominant males may have higher energy requirements than subordinate females (Hogstad 1987). Males undertake most activities associated with territorial defence (Higgins \& Peter 2002) and produce full song year-round (Powlesland 1983). Females, conversely, participate little in maintaining territorial boundaries and never produce full song (Powlesland 1983). Alternatively, sexes may have similar energy requirements and male dominance of food resources could be compensated by female acuity in other aspects of foraging proficiency. The use of different food use tactics by competing subjects has been shown experimentally in a behavioural comparison of two rodent species (Heteromyidae) (Leaver \& Daly 2001). While the dominant species was found to have better access to food, it was correspondingly more susceptible to cache pilferage by the subordinate species.

Powlesland (1981) found that earthworms greater than 4cm in length generally took about 30 seconds to be killed, dismembered and consumed. The time taken to use earthworms is similar to the time taken to handle mealworms of a similar size $(\bar{x}$ = 29sec). This indicates that mealworms were treated similarly to naturally foraged 
prey. Birds used food faster in the breeding season of year two than year one. Interannual variation may be a reflection of differing foraging proficiencies between the individuals sampled in each year, or to different environmental factors encountered. Spring of year two was characterised by very low rainfall (57\% of average) (NIWA 2006). This may have inhibited the activity of soil inhabiting invertebrates such as earthworms (Moeed \& Meads 1985), which are the main prey of robins (Powlesland 1981). Consequently, birds in the breeding season of year two may have used food faster because of greater food needs.

\section{Indecision and aggression}

During the breeding season, males responded positively to females, showing indecision in their haste to transport food to females and young. Moncrieff (1932), similarly, noted that "the robin... we attracted appeared to be actuated by the desire to cram as many morsels as possible into its bill and then to fly off with them”. More accurately, Soper (1976) later observed that breeding birds often showed indecisive behaviour when presented with an excess of mealworms; noting that birds with a full beak of mealworms would often attempt to take on additional items at the expense of those already in their beak.

Armstrong et al. (2000) found that during the breeding season males usually call the female over from any location within their territory. However, males seek solely to feed females, never to encourage females to feed themselves. While simply leading a female to food may enhance direct reproductive fitness, by feeding food directly to the female, males may also enhance and reinforce their status and perceived foraging proficiency. In this study, males were sometimes seen copulating 
with females following courtship feeding, indicating that food may have been offered as an enticement. Alternatively, indecision may be symptomatic of an inability to use an unusual abundance of food. $2 \mathrm{~g}$ of mealworms could be an above average quantity of food for robins. However, it does not exceed the weight of many commonly encountered prey items, such as large weta and earthworms (see Miller \& Walker 1971).

Outside of the breeding season, males generally responded negatively towards females. In this study, males were found to be highly aggressive towards their mate during this period (see also Alexander et al. 2005). Powlesland (1981b) concluded similarly, although he also found that mainland males appeared to be more accepting of their mates than island males. While island males would generally subdivide their territory with females in winter (see also Armstrong et al. 2000), mainland males would allow the female to feed in close proximity. Mainland males were thought to be more accepting of their mates because of greater prey availability on the mainland.

Because of the isolating effect of its predator proof fence, it is unclear which of the scenarios described above applies to KWS robins. In some instances, sexes appeared to be roughly subdividing their territories during the non-breeding season, while, in others, birds were mostly found closely accompanying one another. Some aggression was also observed during the breeding season. Aggression in breeding birds appeared to be largely because of adults removing juveniles from their territory after fledging. Males were occasionally aggressive towards breeding females, but never during brooding. 
In this study, robins were frequently aggressive towards other bird species, especially those that ventured near their cache sites (see also Powlesland 1981b). Antagonism in robins is well established in the literature (see Higgins \& Peter 2002). In Kaikoura, Flack (1976) found that bellbirds were the only species that robins did not dominate in aggressive encounters. However, in the KWS robins were frequently displaced by other bird species, including blackbirds, bellbirds, hihi, and tui. In addition, Powlesland (1981) found that robins would flee from magpies (Gymnorhina tibicen), New Zealand kingfishers (Halcyon sancta) and Australasian harriers (Circus approximans).

\section{Consumption}

A small portion of food was generally consumed before caching or feeding to conspecifics (see also Moncrieff 1932; Powlesland 1980; de Kort et al. 2006). Immediate consumption is consistent with the supposition of Powlesland (1981b) that the first priority of a robin is to find enough food to meet maintenance requirements. Food was devoured after minimal handling. During the non-breeding season, sexes consumed similar proportions. However, both sexes ate less food in the breeding season. Breeding males ate only a small proportion and significantly less than breeding females. Moncrieff (1932), similarly, never observed males consume food while feeding conspecifics.

During the breeding season, males often fed females. Therefore, reduced female consumption from foraging during the breeding season could be explained simply by an increase in mate provisioning. Armstrong et al. (2000) noted that females receive most of their food from their mates during the breeding season. 
However, it is difficult to account for why males consume so little of the extra food provided during the breeding season. Powlesland (1981) found that during incubation, males spend $93 \%$ of their time searching for prey. Perhaps males spend so much time foraging during this time of year that they have already met their immediate energy requirements. Extra food during this season is then immediately either fed to conspecifics or cached. Interestingly, Armstrong et al. (2000) found that males in the breeding season would sometimes consume all mealworms provided to them if more than about 50m from the nest. As females always accompanied males during trials, male consumption may be determined by female presence. Males that consume little in the presence of mates could be perceived to be good providers and thus increase their chances of future reproductive events.

\section{Food sharing}

Feeding of mates and juveniles was common during breeding. Although only adult males would feed adult females, both sexes would contribute to feeding young. Males appear to have a greater responsibility for feeding co-dependents, offering a higher proportion of their food to conspecifics. Unlike males, females have a large direct investment in reproduction, being solely responsible for nest building, egg production, and brooding. A higher direct investment is compensated by a lower indirect investment in conspecific feeding. Males may substitute a lower direct investment in reproduction than females (Wheelwright 1986), with a higher indirect investment in conspecific feeding.

When presented with mealworms during the breeding season, males and females that were initially unaccompanied responded differently. Males generally 
made prodigious vocal attempts to notify their mate (see also Powlesland 1983), while females were silent. Therefore, while males may recognise opportunities afforded to them by providing for their mate, females appear to obtain no benefits from reciprocating. The male may derive reproductive benefits by providing for his mate. Offering additional food may help feed his offspring both, directly; through food subsequently fed to his offspring and, indirectly; by supplementing her diet, and thus enhancing her ability to forage food for the young. Further, the act of providing for the female may enhance his apparent fitness and thus increase the possibility of reproductive events in the future.

Two males were observed courtship feeding earlier (late-August) in 2005 than those in 2004. These two instances occurred about five days before the breeding season specified in this study. An earlier commencement of breeding may be because of the unusually warm temperatures encountered in 2005, which were the third highest on record for the area (NIWA 2006). Especially warm conditions may prompt birds to commence breeding earlier than normal. Birds do occasionally begin breeding outside of mean time periods, but this does not preclude the delineation of general breeding period categories (see Armstrong et al. 2000; Powlesland et al. 2000) to conceptualise predominant seasonal patterns in food use.

Males would frequently drop a large proportion of mealworms in attempts to feed conspecifics, while females dropped a smaller proportion of mealworms during feeding. The smaller number dropped by females is likely related to the smaller number of mealworms transported per feeding event. However, males also dropped more mealworms while feeding females than when feeding juveniles. The propensity 
to drop food may be associated with the speed at which the facilitation of food takes place. Curiously, males are likely under more direct competition for food from adult females than from juveniles. This is because females will readily help themselves to the food source, while juveniles are inclined to wait to be fed. As previously explained, males may derive benefits from feeding females directly. Therefore, food is transported to females more hastily than it is to juveniles as, failing this, females will begin to use the resource independently.

\section{Caching}

Robins cached food throughout the year. Powlesland (1980) found that wild caught, cached food generally consisted of large prey that were broken up before caching, usually while consuming a small portion. Consuming a small amount before caching is consistent with the robin response to mealworms observed here. Similar to large items, $2 \mathrm{~g}$ of mealworms constitutes a source of food over and above that necessary to satisfy immediate energy requirements. Cache concealment consisted solely of attempts to find suitable holes or crevices to cache food items. Items were never actively concealed by covering with other material, as has been reported in nuthatches (Sitta spp.) (Kilham 1972).

Although males cached more food during the non-breeding than the breeding season, female caching intensity did not vary significantly by season. The lack of seasonal variation in female caching intensity may be explained by the input of male courtship feeding during breeding. Males would feed large quantities of mealworms to females up to and past the point of satiety. Therefore, the mealworms obtained by females for themselves during breeding were often not necessary to meet immediate 
energy requirements and, especially between broods, were subsequently cached. As males provided the primary source of food for juveniles during trials, females were still regularly presented with an excess of food in the breeding season. Therefore, during the breeding season, when males were caching little, females continued to cache at similar levels to the non-breeding season. Males, then, cached more than females in the non-breeding season, but less during breeding.

Burns and Steer (2006) also found that males cached a higher proportion of food than females in the non-breeding season. Powlesland (1980), similarly, found that food-caching behaviour occurred most frequently from April to July (mid-autumn to mid-winter). Further, the reduced caching intensity of male robins during breeding is consistent with that of male parids (Paridae) (Pravosudov 2006). Seasonal and intersexual variation in robin caching behaviour is most likely explained by a combination of changes in food availability (Skoczen 1961), energy demand (Vander Wall 1990; Hernández 1995; Pravosudov 2006), and social interactions (McNamara et al. 1990).

\section{The effect of food availability on caching}

No significant seasonal fluctuations in incidental food use were discerned during this study, other than during late summer, when cicadas were noticeably abundant. Powlesland (1981) showed that there is considerable seasonal variation in the species of food taken. However, large invertebrates uniformly form the bulk of biomass, especially earthworms, which comprise 69\% of cached food (Powlesland 1980). 
Spring and summer offer more sunshine, less rainfall, and longer daylight hours than autumn or winter (NIWA 2006). Conditions in spring and summer, therefore, favour aerial and arboreal invertebrate activity (see Hurnard 1978). For insectivores, higher temperatures (Moeed \& Meads 1986) and clear days generally equate to increased invertebrate abundances and perceptivity and thus a higher return on foraging effort (Hernández 1995). Powlesland (1981) found that the behaviours used to obtain prey did not differ between the breeding and non-breeding seasons, although he did find that scanning, hawking, and flycatching appeared to diminish during winter. This was speculated to be associated with lower prey visibility or abundances. Correspondingly, Moeed and Meads (1992) found a higher abundance of invertebrates in summer than in winter in a Hawke’s Bay mixed native forest (see also Moeed \& Fitzgerald 1982). However, in a broader study on Wellington's forest invertebrate fauna, Moeed and Meads (1985) found the highest abundances in autumn, followed by spring, summer, and winter. While in a study on both native and introduced forests, Clout and Gaze (1984) found no evidence for seasonal patterns.

Murphy and Kelly (2003) assessed the seasonal availability of bellbird food resources. They found that the energetic value of invertebrate prey did not vary significantly on bark, but that prey on foliage did vary seasonally, with a peak in December. However, the study only looked at the likely foraging sites of bellbirds, which forage mostly in disparate areas to robins. Unlike bellbirds, soil and leaf litter invertebrates form the bulk of robin prey, with ground gleaning and scanning activities comprising 95\% of foraging time (Powlesland 1981). Terrestrial invertebrates inhabit a more stable seasonal environment than aerial or arboreal 
invertebrates. For instance, the temperatures in soil and leaf litter fluctuate little compared to ambient temperatures.

“As the non-breeding season progressed robins spent more time storing food, even though they spent fewer hours per day foraging” (Powlesland 1980). Conditions in spring and summer may not be favourable for insectivory. Powlesland (1981) speculated that, in summer, robins might only choose partial frugivory as a way of supplementing their diet during dry conditions, when soil invertebrates may be hard to find. As fruit has a lower nutritive value than animal matter, it was concluded that fruit would only be taken during poor invertebrate foraging conditions. Prey was thought to be occasionally scarce in summer because of dry weather; inhibiting the activity of invertebrates and reducing the ability of birds to probe the soil (see also Moeed \& Meads 1985). In addition, competition for invertebrates may increase in spring and summer as partial insectivores, such as tui, bellbirds, and hihi, increase their feeding on insects for protein during breeding (see Koenig \& Mumme 1987; Poulin et al. 1992). The length of time an item is able to be cached may also affect robin food-caching decisions. The maximum duration of food caches is usually shorter during summer (Korpimaki 1987). Higher temperatures lead to faster rates of decay and spoilage.

Fluctuations in robin food availability need to be placed in context with northtemperate food-caching species. Many north-temperate food-caching birds inhabit climates characterised by considerable environmental instability (Roberts 1979; Pravosudov \& Lucas 2001; Broggi et al. 2003). In these environments, annual fluctuations in climate are extreme (ref. Fig. 3). Summers are hot and dry, in winter it 
often snows. Prey abundances in these environments fluctuate considerably. In spring and summer, breeding intensifies, leading to an increase in invertebrate abundances (Gill 1990; Pravosudov 2006). In winter, alternatively, many animals go into dormancy or migrate to avoid freezing conditions. Prey abundances at this time are low (Roberts 1979; Moeed \& Meads 1986; Pravosudov 2006). Many north-temperate birds rely on consuming seeds, which have a lower nutritional value than insects (Koenig \& Mumme 1987).

Despite sharing the temperate clime with north-temperate birds, robins inhabit an environment more closely approximated by tropical conditions (Moeed \& Fitzgerald 1982; Heather \& Robertson 2005). The seasonal variation in climate is not as marked as many north-temperate areas (Hurnard 1978; Moeed \& Fitzgerald 1982; Chan 1994). In comparison to continental landmasses, New Zealand is buffered against climatic fluctuations by a stronger maritime influence. Invertebrate abundances (Moeed \& Fitzgerald 1982; Moeed \& Meads 1986) and activity levels (Moeed \& Meads 1985) fluctuate relatively little. In addition, the New Zealand forest is composed predominantly of closed-canopy evergreen species that, to some extent, insulate forest fauna from seasonal fluctuations (Moeed \& Meads 1985). Temperatures within closed-canopy forests fluctuate less than treeland or grassland environments. In comparison to many north-temperate areas, where the bulk of foodcaching research has been conducted, robins inhabit a relatively stable, equitable environment. Under these conditions, food-caching propensity may be determined more by energy requirements than food supply. During breeding, caching birds that inhabit relatively stable environments might be expected to cache less food because of higher immediate food requirements. 
The effect of energy demand on caching

The energy demands of robins noticeably fluctuate during the year. Robins begin their yearly moult in late summer (St. Paul 1976), and, in winter months, additional energy is required to keep muscles warm through colder days and longer nights (Powlesland 1981b; Pravosudov \& Grubb 1998b; Johannesen et al. 2002). While autumn and winter offer cooler temperatures and shorter day-lengths (NIWA 2006), spring and summer may be the most energetically demanding. "The idea that late winter is difficult for birds has been fixed in ornithological literature, although without direct evidence” (Lahti 1998). For the male robin, the breeding season requires intensive foraging to provide for up to five birds at once (see also Pravosudov 2006). In addition to meeting their own requirements, males provide most of the female's food (Armstrong et al. 2000), and the food of 1-3 juveniles. Males also have to spend considerable time and energy courting mates (see also Brooke \& Birkhead 1991) and defending territories (see Tinbergen 1953). Powlesland (1980) noted that caching was seen only infrequently during the breeding season as additional food was generally fed to mates or young. Females are similarly burdened by the requirements of egglaying and providing additional food for juveniles (Wheelwright 1986; Brooke \& Birkhead 1991). After feeding co-dependents for over two months, birds begin to moult in late summer. Moulting birds may reduce non-foraging activities during the moult, concentrating instead on satisfying the increased protein and energy demands of feather growth (Powlesland 1983). Males sing least during this period, possibly indicating a scarcity in available energy (Powlesland 1983). 
Long daylight hours in spring and summer provide additional foraging time (Powlesland 1981). However, as foraging is more energetically expensive than roosting (Lill 1991; Godfrey 2003), longer daylight hours may provide little additional energy to birds faced with higher indirect energy requirements. In any case, previous studies have shown that enhanced caching rates may occur while day length is increasing or decreasing, revealing that the behaviour is not under strict photoperiodic control (Pravosudov 2006). In a study on seasonal activity patterns of the New Zealand native rifleman (Acanthisitta chloris), birds were found to adjust their activity according to the prevailing conditions. In winter, birds experienced shorter daylight hours and increased thermoregulatory costs than in autumn, but were compensated by increased prey availability. Individuals in winter reduced their energy expenditure by 23 to $29 \%$ while still catching $78 \%$ more prey per day. Prey capture rates may have been enhanced in winter by reduced prey mobility because of lower ambient temperatures, and because of the observed 35\% lower bird population densities (Lill 1991). In another study, Karasawa (1976) observed that shrike (Laniidae) impaling behaviour, similarly, appeared to be density dependent. As the number of shrikes on a territory decreased the number of impalements increased.

Adult mortality is lowest in the breeding season (Powlesland 1983b) and highest in autumn (Flack 1975; Powlesland 1983b), thus population densities are likely lowest in winter (see also Johannesen et al. 2002). Mortality could be attributed to more demanding foraging conditions. However, higher adult mortality rates in the non-breeding season may simply be a factor of higher predation rates (Powlesland 1983b). During the breeding season, predators can feed on high numbers of relatively easy prey such as eggs and juveniles, of both robins and other species. In the non- 
breeding season, when these food sources no longer exist, predators are forced to switch to more difficult adult prey (see Cuthbert et al. 2000). Powlesland (1983b) found that as the breeding season progressed mortality of fledglings increased, perhaps in tandem with predator success.

In the absence of an experimental provision of extra food, robins may cache little in the breeding season (see also Powlesland 1980). However, if robins were caching food to overcome short-term food scarcities (viz. Smith \& Reichman 1984; Vander Wall 1990) this would be the most important time of year to do so. Breeding success is the primary determinate of heritable traits. Birds that produce more offspring pass more of their genetic material to the next generation. Smith and Reichman (1984) posited that animals should cache food just prior to when it is required. Owing to higher energy requirements, robins are more likely to suffer shortages in the breeding season. In addition, offspring are more poorly equipped to survive food scarcity than are adults.

\section{$\underline{\text { Social interactions and caching }}$}

Robins tended to cache food in numerous different sites, regularly caching more than one item in each site. The dispersed nature of these cache sites is consistent with what has been described as scatter hoarding (see Vander Wall 1990). However, regularly returning to cache additional items in the same site may align their behaviour more closely with larder hoarding. Instead, robins undertake a mixture of the two strategies, whereby food items may be scatter or larder hoarded according to factors such as the presence of con- or heterospecifics, season, sex, and perhaps age. 
Larder hoarding food is seen as a strategy befitting an organism that is well placed to defend it, as accumulating food in any quantity makes it an especially rewarding target for pilferers (Bardin \& Markovets 1991; Dally et al. 2006). Scatter hoarding, in contrast, may be a strategy pursued by individuals that are not willing or able to defend their caches (Dally et al. 2006). The inconspicuous nature of scattered reserves may be the best form of protection (Vander Wall 1990). Intersexual variation in cache dispersion in robins may be best explained by the effect of conspecific social interactions (Dally et al. 2006; Murray et al. 2006). Females, in both seasons, tend towards scatter hoarding, caching in more sites than the opposite sex (see also van Horik \& Burns 2006). Males, alternatively, are more disposed to larder hoarding. As males are dominant to females, this may be a consequence of the increased risk of cache pilferage in females. Though males are able to guard their caches to some extent, females are unable to defend theirs; instead relying on dispersion to increase the difficulty of pilferage (Lahti et al. 1998). Alexander et al. (2005) similarly suggested that females might cache less frequently to avoid pilferage by males. Before females cached food they often moved out of sight of the male (see also Powlesland 1980). Females also appeared to cache food further from the point of acquisition than males (see also van Horik \& Burns 2006). Greater cache dispersion by females is consistent with earlier studies, suggesting that subordinates should cache further from the point of acquisition to reduce potential cache pilferage (Brodin 1993; Cristol 2001).

Burns and Steer (2006) compared caching rates between birds surveyed alone or accompanied by a mate during the non-breeding season. They found that caching rates declined for both sexes when accompanied by a mate. However, accompanied 
females showed a more pronounced drop in caching rates than males. They speculated that this might be because the female, as a subordinate, would be more susceptible to cache pilfering. In this study, males often stayed in close proximity to cache sites, frequently chasing away their advancing mate. Reduced rates of caching in the presence of conspecifics show that there is a trade-off between consuming and caching (Carrascal \& Moreno 1993). Brotons (2000) found that coal tits (Parus ater) avoided caching in the presence of close conspecifics, but cache normally at more than $5 \mathrm{~m}$ distance. If food is liable to be rapidly usurped, caching may only be an adaptive response to competition when practiced covertly (see Waite 1992; Heinrich \& Pepper 1998). Soper (1984) described robin caches as "food storage larders known and frequented by both birds in a pair”. However, results suggest that both sexes cache food in a manner that is least conductive to communal use. Instances in which birds remove food from the cache of a mate are more likely examples of reciprocal cache pilferage (see Vander Wall \& Jenkins 2003).

Any movement towards greater cache dispersion in robins (scatter hoarding) is likely a response to the threat of cache pilferage (see Brodin 1993; Dally et al. 2006). In the non-breeding season, both sexes made more cache sites than in the breeding season and transported more mealworms per caching flight. Breeding birds may cache in more condensed aggregations because of the perceived preoccupation of their mates. Breeding females spend considerable periods on the nest where their view of male activities may be considerably obscured. Males, similarly, spend the majority of their time actively foraging in the lower understorey for food for juveniles. Both sexes may be least aware of the position of their mates at this time. Consequently, the 
perceived security of both male- and female-made caches may be higher during breeding.

The decline in male caching rates in the breeding season may also be explained by an increase in conspecific densities (see Stone \& Baker 1989; Murray et al. 2006). Birds in the non-breeding season are susceptible to cache pilferage by mates and unfamiliar conspecifics (Carrascal \& Moreno 1993). However, in the breeding season, caches may also be pilfered by juveniles (Vander Wall \& Jenkins 2003). Nevertheless, in this study juveniles were never seen to use or come close to cache sites. Therefore, it is unlikely that the increased density of birds provided by the uptake of fledglings would be a cause of significant cache loss in the breeding season. However, robin cache dispersion and intensity may also be restricted by the threat of interspecific cache pilfering. Higher heterospecific population densities during breeding may lead to more opportunities for cache pilferage.

Numerous studies have shown that food-caching passerines frequently suffer high levels of pilferage (Bardin \& Markovets 1991). Lack of knowledge regarding the location of food caches may not be a barrier to obtaining the caches of other birds, especially if caches are located in areas that are frequently foraged (Dally et al. 2006). Although Powlesland (1980) did not directly observe interspecific cache pilfering, it was found that robins were especially territorial around their caches. Powlesland (1980) suspected brown creepers (Finschia novaseelandiae), bellbirds, and Turdus spp. of cache pilfering. In this study only one instance of interspecific cache pilfering was observed. However, this was possibly a consequence of the relatively short 
duration of observations during feeding trials. In any case, there is no significant evidence to suggest that robins suffer seriously from interspecific cache pilfering.

\section{Retrieval}

Robins frequently cached food in sites that had been used in previous days and months. Prey was transported directly, and sites were often selected before flight, indicating predisposition. Readily locating and repeatedly using sites indicates that robins may frequently re-use favoured sites, depending on the area in which they happen to be foraging. However, occasionally, different birds were seen to cache in the same cache site during different trials, indicating that, rather than choosing favoured sites, birds may instead have favoured types of sites. Independent squirrels (Sciurus spp.), similarly, often cache nuts in the same sites as other squirrels (in RiceOxley 1993). In laboratory experiments on black-capped chickadees (Parus atricapillus), Baker and Anderson (1995) found no evidence for individuals avoiding previously pilfered sites. Therefore, retrieval may sometimes consist simply in searching in the same types of cache site. If an individual is searching in its own territory, it is likely to find its own caches. However, while searching for the same types of sites in another's territory, it may have a reasonable chance of finding the caches of others.

Retrieval of mealworm caches was seen infrequently during the study period. A relative paucity of retrieval observations may be associated with 1) the short observation period (<15min), 2) the quantity of mealworms provided, or 3) the early time of day. However, when caching naturally foraged food items, robins similarly retrieve little food initially (Powlesland 1980). In a recent experiment, Burns and van 
Horik (2006) experienced greater rates of retrieval after providing twice the number of mealworms (see Bardin \& Markovets 1991), doubling the observation period, and conducting feeding trials later in the day. Exactly which of these factors led to the observed increase in retrieval rates is unclear. However, the superabundance of food may be the primary cause. Under natural conditions, it is rare for such a concentrated abundance of food to present itself. A natural abundance, such as during late summer when cicadas emerge and breed, is generally more spatially dispersed. In this case, there are still many accessible items of food to obtain by foraging following caching. On the contrary, when a robin finishes caching an artificially provided abundance, it may then find that its own caches are the most readily accessible source of food (see also Bardin \& Markovets 1991). When willow tits (Parus montanus) cached food from several feeders, cache retrieval was slower than when presented with one feeder (Brodin 1992).

Instances were observed in which both sexes retrieved their own caches during the observation period. However, females were more frequently observed taking food from male-made caches than vice versa (see also Burns \& van Horik 2006). Retrievals from male caches may compensate the female for losses associated with scatter hoarding, such as a decline in recall accuracy, and possibly, an increase in pilferage by other, non-mate conspecifics. Alternatively, pilferage of male caches may compensate females for a reduced initial acquisition rate because of male dominance. The accuracy of cache recovery in jays (Corvidae) appears to decline as the number of caches increases (Bednekoff et al. 1997). Similarly, although caching at a long distance from the point of acquisition in robins could reduce immediate pilferage, this benefit may be reduced by the presence of other potential pilferers (Komoroski 2001). 
Food items cached towards the periphery of territorial boundaries may also be subject to pilferage as, relative to the centre of the territory, they are likely to be less rigorously monitored (Brotons 2000). However, the intersexual differences in retrieval in this study may be more easily explained by differences in the number acquired. The discrepancy between the male and female's initial share of extra food may be balanced, to some extent, by an increase in female pilferage following caching.

In this study, initial returns to previously cached items were generally not accompanied by consumption. However, retrieval of food may be in response to numerous other factors. For instance, once an individual has secured its food in caches, it may immediately begin using the food resource in ways that are not associated with direct consumption. Bardin and Markovets (1991) described how food-caching tits (Parus spp.) and nutcrackers (Nucifraga spp.) appear to cache food in two stages. Food is initially cached close to the point of acquisition and later re-cached further from the source. The authors concluded that by verifying the retention of caches, birds were able to learn to hide food in the most secure locations.

Alternatively, cache retrieval could be a way of remembering the location of items (Bardin \& Markovets 1991; Brodin 1994), a guarding activity to warn potential competitors (in Dally et al. 2006), or a way of furthering the distribution of caches to insure them against pilferage (Pravosudov \& Grubb 1997). However, another explanation is that the initial purpose of food-caching could be to remove a conspicuous food item from the threat of competition (Lahti et al. 1998), and/or to remove the caching individual from the threat of predation (Cowie et al. 1981; Heinrich \& Pepper 1998; Onuki et al. 2005). An abundance of food will attract 
competitors and predators. Once food is removed from immediate danger, items may be resumed and cached more carefully, and perhaps, covertly, to reduce the threat of subsequent pilfering (Vander Wall et al. 2006).

As has been discussed previously, spatial memory of the location of cached food does not guarantee retrieval by the individual that cached it (Bardin \& Markovets 1991; van Horik \& Burns 2006). Robin cache sites are pilfered by both con- (Burns \& Steer 2006) and heterospecifics (Steer \& van Horik unpublished manuscript). In this study, retrievals from cache sites of the opposite sex were accompanied by consumption of part, or all of its contents. Conspecifics are the most likely cache pilferers, as they tend to use the same or similar feeding niches (Brodin 1993; Lahti \& Rytkönen 1996; Murray et al. 2006). However, cache pilfering by unfamiliar conspecifics is unlikely to be common in robins, as birds tend to inhabit exclusive territories that are rigorously defended. Powlesland (1981) found that gleaning from vegetation comprised about $4 \%$ of foraging time. Vegetation gleaning includes searching amongst holes, fissures, crevices, and branch and trunk axils. All of which represent common cache sites. Birds involved in vegetation gleaning may be searching for hidden cache sites of conspecifics. Alternatively, vegetation gleaning may simply lead to cache pilfering through incidental discovery. However, as most vegetation gleaning is below the average cache height (see Powlesland 1980, 1981), it is unlikely that vegetation gleaning would lead to significant rates of cache pilferage (see also Dally et al. 2006).

Further, if cache pilfering were common enough to affect the integrity of caches then robins would cache during periods of food abundance, because potential 
thieves have less incentive to spend time looking for cached food when it is ubiquitous. However, male robins increase their caching during the non-breeding season, when prey abundances may be relatively low. In any case, cache pilfering need not be a significant detriment to food-caching. "If a given hoarded item is sufficiently more likely to be found by the hoarder than by other individuals, hoarding may be adaptive even in the presence of non-hoarding group mates” (Anderrson \& Krebs 1978).

Powlesland (1980) showed that robins appear to cache and retrieve food on a daily cycle whereby food is more readily cached in the early hours of the day and more readily retrieved in the later hours. Many studies have shown that short-term food-caching birds appear to follow diurnal rhythms in caching behaviour, whereby individuals cache a greater proportion of food earlier in the day and retrieve a greater proportion later (Waite \& Grubb 1988; McNamara et al. 1990). Thus, low rates of retrieval in this study may be because observations were made during the early hours of the morning. Using food later in the day, especially before roosting, may be a way of helping to sustain birds through the night (Powlesland 1980). Maintaining a lower daily body weight may also make birds more efficient foragers and/or reduce the likelihood of predation (Vander Wall 1990). However, this appears to be contradicted by studies on silky pocket mice (Peromyscus maniculatus) (Wolff and Bateman 1978) who retrieve and consume caches just before foraging. Apparently, this provides an immediate source of energy to enhance the efficacy of the activity. Further, American crows (Corvus brachyrhynchos) cache more often later in the day (Cristol 2001). "The longer a bird has been active, the less likely it is to need to consume food immediately to meet its daily energy needs” (Cristol 2001). 
As foraging is more energetically expensive than roosting (Brooke \& Birkhead 1991; Lill 1991; Godfrey 2003), it is more likely that robins would use food before and during the former. Foraging and other daytime activities are hugely energy expensive. Roosting birds, alternatively, spend the majority of the night sitting motionless on a perch insulated by a relatively thick barrier of expanded plumage. Chaplin (1973) found that roosting black-capped chickadees reduced their hourly energy expenditure 23\% by reducing their body temperature. In addition, Chan (1994) concluded that overnight energy requirements and expenditure in the silvereye, a small New Zealand native passerine, are generally less than those shown in northtemperate passerines. In robins, the increasing use of cached food later in the day may be in response to reduced prey availability (Hutto 1981b), foraging proficiency (Holmes et al. 1978), susceptibility to predation (Pravosudov \& Lucas 2000, 2001; Onuki et al. 2005), or the demands of other activities such as territorial defence (see Hernández 1995; Pravosudov \& Grubb 1998; Brotons 2000). 


\section{REFERENCES}

Alexander, L., C. Duthie, et al. (2005). "An experimental evaluation of food hoarding by North Island robins (Petroica australis longipes)." Notornis 52: 138-142.

Anderrson, M. and J. Krebs (1978). "On the evolution of hoarding behaviour." Animal Behaviour 26: 707-711.

Armstrong, D. P., J. G. Ewen, et al. (2000). "Breeding biology of North Island robins (Petroica australis longipes) on Titirangi Matangi Island, Hauraki Gulf, New Zealand." Notornis 47: 106-118.

Baker, M. C. and P. Anderson (1995). "Once-pilfered cache sites not avoided by black-capped chickadees." Animal Behaviour 49: 1599-1602.

Balgooyen, T. G. (1976). "Behavior and ecology of the American kestrel (Falco sparverius) in the Sierra Nevada of California." University of California Publications in Zoology 103: 1-83.

Bardin, A. V. and M. Y. Markovets (1991). "Rate of plundering of reserves stored by tits: Experimental investigation." Soviet Journal of Ecology 61: 332-336.

Bednekoff, P. A., R. P. Balda, et al. (1997). "Long-term spatial memory in four seedcaching corvid species." Animal Behaviour 53: 335-341.

Brodin, A. (1992). "Cache dispersion affects retrieval time in hoarding willow tits." Ornis Scandinavica 23: 7-12.

Brodin, A. (1993). "Low rate of loss of willow tit caches may increase adaptiveness of long-term hoarding." The Auk 110(3): 642-645.

Brodin, A. (1994). "Separation of caches between individual willow tits hoarding under natural conditions." Animal Behaviour 47: 1031-1035.

Broggi, J., K. Koivula, et al. (2003). "Seasonality in daily body mass variation in a hoarding boreal passerine." Oecologia 137: 627-633.

Brooke, M. and T. Birkhead, Eds. (1991). The Cambridge encyclopedia of ornithology. Cambridge, Cambridge University Press.

Brotons, L. (2000). "Individual food-hoarding decisions in a nonterritorial coal tit population: the role of social context." Animal Behaviour 60: 395-402.

Burns, K. C. and J. Steer (2006). "Dominance rank influences food hoarding in New Zealand robins Petroica australis." Ibis 148: 266-272.

Burns, K. C. and J. van Horik (2006). "Sexual differences in food re-caching by New Zealand robins." Journal of Avian Biology In press. 
Carrascal, L. M. and E. Moreno (1993). "Food-caching versus immediate consumption in the nuthatch: the effect of social context." Ardea 81: 135-141.

Chan, K. (1994). "Winter body mass and overnight energetics of a south temperate passerine." The Auk 111(3): 721-723.

Chaplin, S. B. (1974). "Daily energetics of the black-capped chickadee, Parus atricapillus, in winter." Journal of Comparative Physiology A: Neuroethology, Sensory, Neural, and Behavioral Physiology 89(4): 321-330.

Clout, M. N. and P. D. Gaze (1984). "Effects of plantation forestry on birds in New Zealand." Journal of Applied Ecology 21: 795-815.

Collopy, M. W. (1977). "Food-caching by female American kestrels in winter." The Condor 79: 63-68.

Cowie, R. J., J. R. Krebs, et al. (1981). "Food storing by marsh tits." Animal Behaviour 29: 1252-1259.

Cristol, D. A. (2001). "American crows cache less preferred walnuts." Animal Behaviour 62: 331-336.

Cuthbert, R., E. Sommer, et al. (2000). "Seasonal variation in the diet of stoats in a breeding colony of Hutton's shearwaters." New Zealand Journal of Zoology 27: 367-373.

Dally, J. M., N. S. Clayton, et al. (2006). "The behaviour and evolution of cache protection and pilferage." Animal Behaviour In press.

de Kort, S. R., N. J. Emery, et al. (2006). "Food sharing in jackdaws, Corvus monedula: what, why and with whom?" Animal Behaviour In press.

Flack, J. A. D. (1975). "Aspects of the ecology of the New Zealand robin Petroica australis." Emu 74(Supplement): 286.

Flack, J. A. D. (1976). "The use of frontal spot and crown feathers in inter- and intraspecific display by the South Island robin, Petroica australis australis." Notornis 23: 90-105.

Gill, F. B. (1990). Ornithology. New York, W.H. Freeman and Co.

Godfrey, J. D. (2003). Energy expenditures of North Island robins in habitats with differing predator densities. Conservation applications of measuring energy expenditure of New Zealand birds: assessing habitat quality and costs of carrying radio transmitters Science for Conservation 214. 95p. M. Williams: 25-34.

Heather, B. D. and H. A. Robertson (2005). The field guide to the birds of New Zealand. Auckland, Penguin Books Ltd. 
Heinrich, B. and J. W. Pepper (1998). "Influence of competitors on caching behaviour in the common raven, Corvus corax." Animal Behaviour 56: 1083-1090.

Hernández, Á. (1995). "Temporal-spatial patterns of food-caching in two sympatric shrike species." The Condor 97: 1002-1010.

Higgins, P. J. and J. M. Peter (2002). Handbook of Australian, New Zealand and Antarctic birds. Volume 6: pardalotes to shrike-thrushes. Victoria, Oxford University Press.

Hogstad, O. (1987). "It is expensive to be dominant." The Auk 104: 333-336.

Holmes, R. T., T. W. Sherry, et al. (1978). "Diurnal and individual variability in the foraging behavior of American redstarts (Setophaga ruticilla)." Oecologia 36(2): 141-149.

Hulls, G. and M. Mellor (eds.) (2005). Spring chorus a prolific one. Kereru 29: 1.

Hurnard, S. M. (1978). "Climatic factors in the seasonality of New Zealand insects: a meteorological viewpoint." The New Zealand Entomologist 6(4): 337-343.

Hutto, R. L. (1981b). "Temporal patterns of foraging activity in some wood warblers in relation to the availability of insect prey." Behavioral Ecology and Sociobiology 9(3): 195-198.

Johannesen, E., H. Steen, et al. (2002). "Seasonal variation in survival, weights, and population counts of blue penguins (Eudyptula minor) in Otago, New Zealand." New Zealand Journal of Zoology 29: 213-219.

Karasawa, K. (1976). "Observations on the impalements made by shrikes." Tori 25(100): 94-100.

Kilham, L. (1974). "Covering of stores by white-breasted and red-breasted nuthatches." The Condor 76: 108-109.

Koenig, W. D. and R. L. Mumme (1987). Population ecology of the cooperatively breeding acorn woodpecker. Princeton, Princeton University Press.

Komoroski, M. J. (2001). "Incidental cache use by the brown thrasher, with notes on secondary cache use by additional avian species." The Chat 65(2): 68-70.

Korpimäki, E. (1987). "Prey caching of breeding Tengmalm's owls Aegolius funereus as a buffer against temporary food shortage " Ibis 129: 499-510.

Lack, D. (1971). Ecological isolation in birds. London, Blackwell Scientific Publications.

Lahti, K. (1998). "Social dominance and survival in flocking passerine birds: a review with an emphasis on the willow tit Parus montanus." Ornis Fennica 75: 1-17. 
Lahti, K., K. Koivula, et al. (1998). "Social influences on food-caching in willow tits: a field experiment." Behavioral Ecology 9: 122-129.

Lahti, K. and S. Rytkönen (1996). "Presence of conspecifics, time of day and age affect willow tit food hoarding." Animal Behaviour 52: 631-636.

Leaver, L. A. and M. Daly (2001). "Food-caching and differential cache pilferage: a field study of coexistence of sympatric kangaroo rats and pocket mice." Oecologia 128: 577-584.

Lill, A. (1991). "Behavioral energetics of overwintering in the rifleman, Acanthisitta chloris." Australian Journal of Zoology 39(6): 643-654.

Lucas, J. R. and L. R. Walter (1991). "When should chickadees hoard food? Theory and experimental results." Animal Behaviour 41: 579-601.

Lyons, D. and J. A. Mosher (1982). "Food-caching by raptors and caching of a nestling by the broad-winged hawk." Ardea 70: 217-219.

McNamara, J. M., A. I. Houston, et al. (1990). "Why hoard? The economics of food storing in tits, Parus spp." Behavioral Ecology 1(1): 12-23.

Miller, D. and A. K. Walker (1971). Common insects in New Zealand. Auckland, Reed.

Moeed, A. and B. M. Fitzgerald (1982). "Foods of insectivorous birds in forest of the Orongorongo Valley, Wellington, New Zealand " New Zealand Journal of Zoology 9: 391-402.

Moeed, A. and M. J. Meads (1985). "Seasonality of pitfall trapped invertebrates in three types of native forest, Orongorongo Valley, New Zealand." New Zealand Journal of Zoology 12: 17-53.

Moeed, A. and M. J. Meads (1986). "Seasonality of litter-inhabiting invertebrates in two native forest communities of the Orongorongo Valley, New Zealand." New Zealand Journal of Zoology 13: 45-63.

Moeed, A. and M. J. Meads (1992). "A survey of invertebrates in scrublands and forest, Hawke's Bay, New Zealand." New Zealand Entomologist 15: 63-71.

Moncrieff, P. (1932). "Notes on the South Island robin." Emu 32: 52-58.

Murphy, D. J. and D. Kelly (2003). "Seasonal variation in the honeydew, invertebrate, fruit and nectar resource for bellbirds in a New Zealand mountain beech forest." New Zealand Journal of Ecology 21(1): 11-23.

Murray, A. L., A. M. Barber, et al. (2006). "Competitive environment affects foodhoarding behavior of Merriam's kangaroo rats (Dipodomys merriami)." Journal of Mammalogy 87(3): 571-578. 
Nellis, C. H. and L. B. Keith (1968). "Hunting activities and success of lynxes in Alberta." Journal of Wildlife Management 32: 718-722.

NIWA. (2006). "National climate centre." from http://www.niwascience.co.nz/ncc/.

NOAA. (2006). "National weather service." from http://www.crh.noaa.gov/bou/.

Onuki, Y., K. Kato, et al. (2005). "Influences of food type on food-carrying behavior in rats (Rattus norvegicus)." Behavioural Processes 70: 182-185.

Poulin, B., G. Lefebvre, et al. (1992 ). "Tropical avian phenology in relation to abundance and exploitation of food resources." Ecology 73(6): 2295-2309.

Powlesland, R. G. (1980). "Food storing behaviour of the South Island robin." $\underline{\text { Mauri }}$ Ora 8: 11-20.

Powlesland, R. G. (1981). "The foraging behaviour of the South Island robin." Notornis 28: 89-102.

Powlesland, R. G. (1981b). "Comparison of time-budgets for mainland and Outer Chetwode Island populations of adult male South island robins." New Zealand Journal of Ecology 4: 98-105.

Powlesland, R. G. (1983). "Seasonal and diurnal variation in vocal behaviour of the South island robin." New Zealand Journal of Zoology 10: 225-232.

Powlesland, R. G. (1983b). "Breeding and mortality of the South Island robin in Kowhai Bush, Kaikoura." Notornis 30: 265-282.

Powlesland, R. G., J. W. Knegtmans, et al. (2000). "Breeding biology of North Island robins (Petroica australis longipes) in Pureora forest park." Notornis 47: 97105.

Pravosudov, V. V. (1984). "The storage of food by the Siberian jay Perisoreus infaustus." Zoologichesky Zhurnal 63: 950-953.

Pravosudov, V. V. (2006). "On seasonality in food-storing behaviour in parids: do we know the whole story?" Animal Behaviour In press.

Pravosudov, V. V. and T. C. Grubb Jr. (1997). "Energy management in passerine birds during the non-breeding season: a review." Current Ornithology 14: 189234.

Pravosudov, V. V. and T. C. Grubb Jr. (1998). "Management of fat reserves in tufted titmice (Parus bicolor): evidence against a trade-off with food hoards." Behavioral Ecology and Sociobiology 42: 57-62.

Pravosudov, V. V. and T. C. Grubb Jr. (1998b). "Body mass, ambient temperature, time of day, and vigilance in tufted titmice." The Auk 115(1): 221-223. 
Pravosudov, V. V. and J. R. Lucas (2000). "The effect of social dominance on fattening and food-caching behaviour in Carolina chickadees, Poecile carolinensis." Animal Behaviour 60: 483-493.

Pravosudov, V. V. and J. R. Lucas (2001). "Daily patterns of energy storage in foodcaching birds under variable daily predation risk." Behavioral Ecology and Sociobiology 50: 239-250.

Rice-Oxley, S. B. (1993). "Caching behaviour of red squirrels Sciurus vulgaris under conditions of high food availability." Mammal Review 23(2): 93-100.

Roberts, R. C. (1979). "The evolution of avian food-storing behavior." The American Naturalist 114(3): 418-438.

Shettleworth, S. J. and J. R. Krebs (1986). "Stored and encountered seeds: a comparison of two spatial memory tasks in marsh tits and chickadees." Journal of Experimental Psychology: Animal Behaviour Processes 12: 248257.

Skoczen, S. (1961). "On food storage of the mole, Talpa europea Linnaeus 1758." Acta Theriol 5: 23-43.

Smith, C. C. and O. J. Reichman (1984). "The evolution of food-caching by birds and mammals." Annual Review of Ecology and Systematics 15: 329-351.

Soper, M. F. (1976). New Zealand Birds. Christchurch, Whitcoulls Publishers.

Soper, M. F. (1984). Birds of New Zealand. Christchurch, Whitcoulls Publishers.

SPSS (2002). SigmaPlot 8.02 for Windows. Chicago, SPSS Inc.

SPSS (2003). SPSS 12.0 for Windows. Chicago, SPSS Inc.

St. Paul, R. (1976). "A bushman's seventeen years of noting birds." Notornis 23: 220232.

Tinbergen, N. (1953). Social behaviour in animals: with special reference to vertebrates. London, Methuen \& Co. Ltd.

van Horik, J. and K. C. Burns (2006). "Cache spacing patterns and reciprocal cache theft in New Zealand robins." Animal Behaviour In press.

Vander Wall, S. B. (1990). Food hoarding in animals. Chicago, The University of Chicago Press.

Vander Wall, S. B., J. S. Briggs, et al. (2006). "Do food-hoarding animals have a cache recovery advantage? Determining recovery of stored food." Animal Behaviour In press. 
Vander Wall, S. B. and S. H. Jenkins (2003). "Reciprocal pilferage and the evolution of food-hoarding behavior." Behavioral Ecology 14(5): 656-667.

Waite, T. A. (1992). "Social hoarding and load size-distance relationship in gray jays." The Condor 94: 995-998.

Waite, T. A. and T. C. J. Grubb (1988). "Diurnal caching rhythm in captive whitebreasted nuthatches Sitta carolinensis." Ornis Scandinavica 19(1): 68-70.

Wheelwright, N. T. (1986). "The diet of American robins: An analysis of U.S. biological survey records." The Auk 103: 710-725.

Wolff, J. O. and G. C. Bateman (1978). "Effects of food availability and ambient temperature on torpor cycles of Perognathus flavus (Heteromyidae)." Journal of Mammalogy 59: 707-716. 


\section{CHAPTER THREE}

\section{SUMMARY AND CONCLUSIONS}

\section{Seasonality of food use and caching in New Zealand robins}

Patterns of food use in robins vary seasonally. Birds respond differently to food in different seasons regardless of whether food is obtained naturally (see Powlesland 1980) or experimentally. Males dominate food use year-round. Outside of breeding, birds consume food to satiety and forage selfishly. Conversely, breeding birds consume a smaller proportion, dividing foraged prey between themselves and their offspring. During breeding, males generally respond positively to familiar conspecifics. Food is transported to mates and young. Oppositely, males respond negatively to familiar conspecifics outside of breeding. Young are aggressively removed from territories, which are then commonly subdivided between mates. Food supply varies relatively little seasonally because of New Zealand's equitable climate. However, reductions in population densities and food demand lead to an excess of food outside the breeding season. Caching intensity thus increases.

Competitive pressure from males causes females to cache less than males, although this may be compensated by uneven rates of reciprocal cache pilferage. As cached food is retrieved within a few days (Powlesland 1980), food-caching roughly approximates temporal food use. Caching intensity is highest during non-breeding when food demand is lowest. Therefore, food-caching in robins may not be a response 
to the threat of food scarcity. Caching during the breeding season is unusual and so, similarly, is unlikely to be related to reproductive success. Instead, caching in robins appears to be primarily an opportunistic competitive response to usurping excess food.

\section{Competition and caching behaviour}

The predominance of competition as a factor explaining the expression of caching behaviour may not be limited to robins (see Murray et al. 2006). Most bird species spend at least a portion of their year in flocks (see Lahti 1998). Even sedentary birds, such as robins, are generally in regular close contact with conspecific competitors on adjoining territories. Although interspecific stealing of food is known to occur in many animal groups, it appears to be particularly widespread in birds (Brockmann \& Barnard 1979). Therefore, competition for food is one of the primary determinants of avian food use. "Wild animals often cache large quantities of food while eating little or nothing” (Clayton \& Dickinson 1999). By removing food from the point of acquisition, birds may reduce their chances of falling prey to terrestrial predators, and of relinquishing food to competitors (Cowie et al. 1981; McNamara et al. 1990; Onuki et al. 2005). Caching is the most secure way of using food when under pressure (Bindra 1948). Reducing the quantity of visible prey on a territory also may make it less enticing to future competitors (Anderrson \& Krebs 1978).

In this respect, caching may be more important than retrieval. Many birds, for instance, are known to forget the location of their caches and to cache outside their territorial boundaries (in Anderrson \& Krebs 1978). In many food-caching species, the natural rate of cache pilferage is high (Hampton \& Sherry 1992; Vander Wall \& 
Jenkins 2003) and retrieval low (Stevens \& Krebs 1986). Robins usually leave their cache site immediately upon depositing prey, moving quickly to obtain additional items. Individuals may be directing energy towards maximising their share of the available resource, perhaps later focusing on the security of cache sites (Rice-Oxley 1993). However, having only a fleeting presence at the cache site also makes it less likely that they will be discovered in the act.

Long-term food-caching in birds is uncommon (see Vander Wall 1990) and predominantly associated with a relatively small number of north-temperate seed caching species (e.g. acorn woodpeckers, jays, nutcrackers). However, conclusions associated with food use in these species are disproportionately represented in the literature. Most cache food intensely during late summer and autumn when seeds ripen. Seed supplies run out in winter, as do other food sources, and retrieval commences. In these species, food-caching enables birds that would otherwise migrate, to reside year-round (in Vander Wall 1990). In this sense, food-caching provides an alternative to migration. Resident birds have the advantage of priority access to the best foraging territories in the following breeding season.

Food-caching behaviour appears to have evolved in birds that are regularly faced with an excess of food, liable to be usurped by competitors, but able to be removed for future use (see Roberts 1979). The principal utility of food-caching for most birds may reside in removing food from the threat of competition and, possibly, in removing themselves from the threat of predation (Cowie et al. 1981; Heinrich \& Pepper 1998; Onuki et al. 2005). In some instances, these caches may have incidentally allowed individuals to cope more easily with future food scarcity. 
However, in many studies, the prominence of food scarcity as a factor explaining the adaptive advantage of caching may have been inflated. Food-caching in birds has been linked to higher latitudes, primarily because high latitude environments present higher levels of environmental variability. Food cached during periods of abundance may be later used when food is scarce (Roberts 1979; Pruett-Jones \& Pruett-Jones 1985). However, greater environmental variability is only one feature of high latitudes. For instance, lower latitudes have higher species diversity (MacArthur \& MacArthur 1961), thus caching propensity may be influenced by increased competition. Here, pressure from interspecific cache parasitism may determine the extent of food-caching (Bardin \& Markovets 1991). Food-caching animals at lower latitudes are also constrained by consistently higher temperatures (Smith \& Reichman 1984) which increase the rate of decay (i.e. cached food needs to be retrieved at a faster rate). In a recent review of food-caching parids (Paridae), Pravosudov (2006) suggested that the intensity of caching behaviour depends on the seasonality of food types available; concluding that any single assumption concerning regular seasonal peaks in caching behaviour may prove misleading.

Food-caching behaviour appears to have evolved independently in numerous unrelated species (Smith \& Reichman 1984; Vander Wall 1990). Therefore, foodcaching may have become extinct in other species (see de Kort \& Clayton 2006). If caching is a competitive response to food excess, then it may be a relatively ephemeral phenomenon. Various conditions can lead to temporary abundances in the environment. However, competition means that abundances are rarely used by a single species. Food-caching birds, therefore, may be a characteristic of nonequilibrial environments. In the absence of sufficient competition, some birds may be 
able to cache food. However, eventually new competitors either evolve, or arrive to fill the void, and caching behaviour then declines. Prominent food-caching species, therefore, may inhabit non-equilibrial environments characterised by a lack of species-specific competitors. Many of the most conspicuous avian food-caching species inhabit north-temperate post-glacial environments (see Pielou 1991), characterised by low species diversity. Conversely, animals that cache little may also inhabit non-equilibrial environments. However, in this case, they are faced with a larger suite of species-specific competitors. Food-caching behaviour, therefore, could be less 'hard-wired' and more plastic and ephemeral than is often acknowledged (see also Emery et al. 2004).

Animals that are faced with no immediate competitive threat to excess food may have no need to cache food. Conversely, animals faced with high levels of competition may find it difficult to hide food discretely without suffering high levels of kleptoparasitism and cache pilfering. Therefore, paradoxically, caching behaviour may only be adaptive in animals faced with neither too little nor too much competition. In a recent study, Murray et al. (2006) concluded that intraspecific variation in the caching behaviour of Merriam’s kangaroo rat (Dipodomys merriami) might be largely associated with variation in competitive environments.

\section{Food-caching and breeding}

Food-caching behaviour has been linked to the breeding season of various animals (Esely \& Bollinger 2003). In some instances, animals may be caching during, or just before the breeding season in attempts to aid feeding of young (Koenig \& Mumme 
1987; Esely \& Bollinger 2003) or courting of mates (Yosef \& Pinshow 2005). However, in many species, especially in north-temperate areas, the breeding season also coincides with the period of maximum prey abundances for juveniles (Gill 1990). Cached food, in this instance, might be related to breeding success, but this is difficult to disentangle from food supply. If an individual's territory yields more food than it is able to consume or feed to co-dependents, it may be able to cache the excess. The frequency of caching, therefore, may be more closely related to territory quality or foraging/competitive ability, than to inherent caching propensity. Bigger caches could simply be a result of more food, regardless of the caching ability of the individual. Abundant food may heighten the chances of offspring survivorship. However, the number or size of caches and breeding success may not be directly related. Birds with more food could cache more than birds with less, even if they are poorer at caching. Instead, prey availability, not cache size, would be the primary determinant of breeding success.

Smith and Reichman (1984) proposed that food-caching behaviour might have evolved from nesting or offspring provisioning behaviour. In the breeding season, robins sometimes cache food close to the nest site, and it has been speculated that this may be to enhance the facilitation of food to the young (see Powlesland 1980). Caching close to the nest means that food could be more easily removed by nesting females or more readily transported to nestlings by males. In loggerhead shrikes (Lanius ludovicianus) the number of impaled prey is highest during the nestling stage. Birds impale food closer to the nest during this stage than in either the incubation or fledgling stages (Esely \& Bollinger 2003). During nesting, 28\% of food fed to mates and juveniles by male loggerhead shrikes come from impaled stores. Therefore, 
impaling in shrikes appears to provide a food delivery function during nesting (Applegate 1977).

In this study, robins in the breeding season were occasionally seen retrieving the contents of their own, or their mate's caches (see also Powlesland 1980). However, the proportion of prey cached by males during the breeding season was lower than the non-breeding season. If food-caching were integral to the facilitation of food to the young and to females, caching rates would be higher during breeding. Instead, male robins feed most of their food directly to conspecifics, only rarely via cache sites. In addition, while shrikes generally impale prey on the periphery of trees where they are visible to females (in Esely \& Bollinger 2003), robin caches are rarely noticeable. Caching location may simply indicate the location of the male's activities. Nests are likely to be placed close to the centre of the territory to aid conspecific feeding and defence. Therefore, caches made nearby may be coincidental.

Brotons (2000) found that coal tits (Parus ater) tend to concentrate their caches in the core areas of their home range. However, caching near nest sites may be deleterious to nestling survival. Northern shrikes (Lanius excubitor) do not cache within 50m of the nest, apparently to avoid attracting thieves and predators to the nest area (in Smith \& Reichman 1984). Similarly, many bird species, including robins (pers. obs.), regularly remove faecal sacs from the nest site in order to reduce the probability of attracting predators to their smell (Tinbergen 1953; Petit et al. 1989). Armstrong et al. (2000) concluded that the most important factors influencing breeding success were habitat limitation and territory acquisition. The relative scarcity 
of caching activity in the breeding season makes breeding activity per se an unlikely determinant of caching activity in robins.

Robins have a longer breeding season than many native forest birds in New Zealand (Powlesland 1980; Gill et al. 1983). The breeding season could be extended by the use of cached food to even out prey fluctuations (Gill et al. 1983). However, again, breeding duration may be only indirectly related to food-caching behaviour. Robins only cache food in small quantities and for a short duration, usually less than 2 to 3 days (Powlesland 1980). Therefore, food caches could only prompt the commencement of breeding by a similarly incremental period. Instead, robins may encounter higher prey abundances earlier in the season. Robin prey availability may be relatively high in autumn (Moeed \& Meads 1985) meaning birds are able to begin breeding as soon as temperatures rise to a level at which offspring are able to survive nesting.

Here it is important to note that enhanced prey abundance during nesting is not the only possible determinant of the timing of breeding. For instance, in house wrens (Troglodytes aedon) breeding begins when prey levels are at an annual low (Young 1994). In this species, it is speculated that the timing of reproduction aids postbreeding activities. Similarly, acorn woodpeckers (Melanerpes formicivorus) are unable to breed during maximum prey abundances in autumn as cool temperatures and the impending winter would lead to reduced survivorship of young. Therefore, the early commencement of breeding in robins is more likely dictated by environmentally determined factors (Cockrem 1995), than by an independently determined provision 
of food. Powlesland et al. (2000) attributed the length of the breeding season in robins to population density and prey availability.

\section{The evolution of food-caching behaviour in New Zealand robins}

Food-caching in robins appears to have evolved as a mechanism for reducing the foraging costs associated with competition. As robins spend $90 \%$ of their foraging time on and within $2 \mathrm{~m}$ of the ground (Powlesland 1981), it is less conceivable that robins would have adopted caching behaviour purely as a means of avoiding terrestrial predation. However, it is difficult to speculate on the effects or extent of past competition on robins. Fleming (1950) inferred that the Petroica genus evolved on the Australian continent, later dispersing to New Guinea and Polynesia. Petroica australis is thought to be a relatively old constituent of the New Zealand avifauna (Fleming 1974). Ancestral precursors of the modern species may have invaded New Zealand as early as the Pliocene (5.3 to 1.8 million years BP) (Fleming 1950b).

Before the widespread extinctions caused by human habitation, New Zealand's terrestrial fauna species were abundant and diverse. Around 33\% of prehuman birds were flightless, with a further $9 \%$ showing reduced powers of flight (Atkinson \& Millener 1990). However, 40 to 50\% of these birds are now extinct (Holdaway 1989). The terrestrial insectivore guild has suffered some of the greatest losses (Atkinson \& Millener 1990). In addition, native reptiles such as skinks, geckos and tuatara were more abundant in lowland and coastal forests (Holdaway 1989; Atkinson \& Millener 1990). Therefore, the paucity of non-introduced terrestrial competitors in the contemporary New Zealand forest may not be indicative of past 
conditions. Robins may have faced a considerably greater suite of native competitors in their pre-human environment.

Food-caching in many mammals consists principally in removing large items from the threat of pilferage (see Vander Wall 1990). Similarly, caching behaviour may have evolved in robins as a way of dealing with unusually large prey items such as native earthworms and weta. Large invertebrates comprise the bulk of robin prey (Powlesland 1980), and, being too large to be swallowed whole, require dismembering. As robins can only consume a small quantity of prey at a time, it is advantageous to be able to guard or hide the uneaten remainder until the first portion has been digested. Any animal faced with a regularly occurring overabundance of food would benefit from developing some kind of mechanism to capitalise on it.

A behavioural precursor to caching may have been in the facilitation of prey to higher elevations to dismember and consume. Robins generally cache food in sites that are higher than 3m in the canopy (Alexander et al. 2005). Handling prey at higher elevations removes food from the threat of terrestrial competition. Moncrieff (1932) described juvenile robins carrying food to a safer dismembering location to devour inconspicuously. The onset of food-caching may simply be a later elaboration on this behaviour.

Robins are the only known food-caching passerine in New Zealand. However, they do not appear to have any physical attributes that might predispose them to foodcaching. Petroica australis is also unique among its genus in being both the largest representative and the only species to cache food. However, it is difficult to speculate 
as to whether these two unique qualities might be related. Prior research does not suggest that the propensity to cache food among species might increase with body size or vice versa. However, Smith and Reichman (1984) indicated that this might be implicated with larder hoarding, implying that larger body sizes were required to defend larder hoarded food. Unlike some food-caching species (see Smith \& Reichman 1984; Bednekoff et al. 1997), robins have no morphological specialisations for internally transporting food (Powlesland 1980). A lack of specialisation may identify food-caching in robins as a relatively recent evolutionary event, or as a behavioural adaptation of low adaptive significance (see de Kort \& Clayton 2006). However, lack of morphological adaptation is not restricted to robins, and includes many species that cache more prolifically (in Vander Wall 1990).

Atkinson and Millener (1990) concluded that the evolution of New Zealand's lowland avifauna has favoured adaptations allowing birds to use the same basic food source in the same forest habitat in different ways. They suggested that evolution in New Zealand has generally not favoured differing avifaunas or guild structures associated with different kinds of forest. In addition, "Differences in hunting methods and feeding stations are at least as important as differences in size of prey in separating congeners” (Lack 1971). The adoption of caching behaviour in robins, therefore, may have been a novel way to exploit an otherwise fully exploited niche.

\section{Suggestions for future research}

In previous research on robins, differences in breeding behaviour, mortality rates (Powlesland 1983b), foraging heights (Powlesland 1981), and sexual variation in 
foraging proficiency (Moncrieff 1932) have been linked to age-related factors. Future experiments could look at differences in caching and other food use behaviours by age. The ontogeny of caching behaviour, especially, has received little prior investigation (see Forslund \& Pärt 1995). In the KWS, robins have previously been colour-banded to reflect the year in which they fledged, thus the approximate age of birds is known. Experiments could compare behavioural variation both between birds of different ages, and between the same birds in different years.

Many non-caching bird species are known to pilfer the cached food of caching species (Bardin \& Markovets 1991), and loss of cached food to robbers is high in some natural populations (Baker \& Anderson 1995). Future investigations could look specifically at the fate of cached food. Although prior research has gone into understanding the duration of caches and the identity of the retriever (Burns \& van Horik 2006; van Horik \& Burns 2006), this topic has room for considerable expansion. Past investigations have identified native bird species (Steer \& van Horik unpublished manuscript), and possibly insects (Barr et al. 1996) as cache pilferers, and it would be interesting to investigate whether exotic bird species or mammals also pilfer robin caches.

Overall, this study highlights the enormous scope for behavioural research on robins, a species that is extraordinarily amenable to observations in the wild. By quantifying the species' year-round responses to food, this research has laid a platform for understanding the motivation behind sexual and seasonal differences in behaviour. The theoretical underpinning of caching behaviour in birds is heavily influenced by the wealth of previous research on north-temperate species. This study 
Summary and conclusions

reveals the potential for new perspectives from work on scarcely considered Southern Hemisphere species. 


\section{REFERENCES}

Alexander, L., C. Duthie, et al. (2005). "An experimental evaluation of food hoarding by North Island robins (Petroica australis longipes)." Notornis 52: 138-142.

Anderrson, M. and J. Krebs (1978). "On the evolution of hoarding behaviour." Animal Behaviour 26: 707-711.

Applegate, R. D. (1977). "Possible ecological role of food caches of loggerhead shrike." The Auk 94: 391-392.

Armstrong, D. P., J. G. Ewen, et al. (2000). "Breeding biology of North Island robins (Petroica australis longipes) on Titirangi Matangi Island, Hauraki Gulf, New Zealand." Notornis 47: 106-118.

Atkinson, I. A. E. and P. R. Millener (1990). An ornithological glimpse into New Zealand's pre-human past. Acta XX Congressus Internationalis Ornithologici.

Baker, M. C. and P. Anderson (1995). "Once-pilfered cache sites not avoided by black-capped chickadees." Animal Behaviour 49: 1599-1602.

Bardin, A. V. and M. Y. Markovets (1991). "Rate of plundering of reserves stored by tits: Experimental investigation." Soviet Journal of Ecology 61: 332-336.

Barr, K., H. Moller, et al. (1996). "Impacts of introduced common wasps (Vespula vulgaris) on experimentally placed mealworms in a New Zealand beech forest." Oecologia 105(2): 266-270.

Bednekoff, P. A., R. P. Balda, et al. (1997). "Long-term spatial memory in four seedcaching corvid species." Animal Behaviour 53: 335-341.

Bindra, D. (1948). "What makes rats hoard?" Journal of Comparative Physiological Psychology 41: 397-402.

Brockmann, H. J. and C. J. Barnard (1979). "Kleptoparasitism in birds." Animal Behaviour 27: 487-514.

Brotons, L. (2000). "Individual food-hoarding decisions in a nonterritorial coal tit population: the role of social context." Animal Behaviour 60: 395-402.

Burns, K. C. and J. van Horik (2006). "Sexual differences in food re-caching by New Zealand robins." Journal of Avian Biology In press.

Clayton, N. S. and A. Dickinson (1999). "Motivational control of caching behaviour in the scrub jay, Aphelocoma coerulscens." Animal Behaviour 57: 435-444.

Cockrem, J. F. (1995). "Timing of seasonal breeding in birds, with particular reference to New Zealand birds." Reproduction, Fertility and Development 7(1): 1-19. 
Cowie, R. J., J. R. Krebs, et al. (1981). "Food storing by marsh tits." Animal Behaviour 29: 1252-1259.

de Kort, S. R. and N. S. Clayton (2006). "An evolutionary perspective on caching by corvids." Proceedings of the Royal Society B 273: 417-423.

Emery, N. J., J. M. Dally, et al. (2004). "Western scrub-jays (Aphelocoma californica) use cognitive strategies to protect their caches from thieving conspecifics." Animal Cognition 7: 37-43.

Esely, J. D. and E. K. Bollinger (2003). "Patterns of impaling in a migratory population of the loggerhead shrike." The Prairie Naturalist 35(1): 1-8.

Fleming, C. A. (1950). "New Zealand flycatchers of the genus Petroica Swainson: Part I." Transactions of the Royal Society of New Zealand 78(1): 14-47.

Fleming, C. A. (1950b). "New Zealand flycatchers of the genus Petroica Swainson (Aves): Part II." Transactions of the Royal Society of New Zealand 78(2-3): 127-160.

Fleming, C. A. (1974). "The coming of the birds." NZ Nature Heritage 1: 61-68.

Forslund, P. and T. Pärt (1995). "Age and reproduction in birds - hypotheses and tests." Trends in Ecology and Evolution 10(9): 374-378.

Gill, F. B. (1990). Ornithology. New York, W.H. Freeman and Co.

Gill, B. J., R. G. Powlesland, et al. (1983). "Laying seasons of three insectivorous song-birds at Kowhai Bush, Kaikoura." Notornis 30: 81-85.

Hampton, R. R. and D. F. Sherry (1992). "The effects of cache loss on choice of cache site in black-capped chickadees." Behavioral Ecology 5(1): 44-50.

Heinrich, B. and J. W. Pepper (1998). "Influence of competitors on caching behaviour in the common raven, Corvus corax." Animal Behaviour 56: 1083-1090.

Holdaway, R. N. (1989). "New Zealand's pre-human avifauna and its vulnerability." New Zealand Journal of Ecology(Supplement): 11-25.

Koenig, W. D. and R. L. Mumme (1987). Population ecology of the cooperatively breeding acorn woodpecker. Princeton, Princeton University Press.

Lack, D. (1971). Ecological isolation in birds. London, Blackwell Scientific Publications.

Lahti, K. (1998). "Social dominance and survival in flocking passerine birds: a review with an emphasis on the willow tit Parus montanus." Ornis Fennica 75: 1-17. 
MacArthur, R. H. and J. W. MacArthur (1961). "On bird species diversity." Ecology 42(3): 594-598.

McNamara, J. M., A. I. Houston, et al. (1990). "Why hoard? The economics of food storing in tits, Parus spp." Behavioral Ecology 1(1): 12-23.

Moeed, A. and M. J. Meads (1985). "Seasonality of pitfall trapped invertebrates in three types of native forest, Orongorongo Valley, New Zealand." New Zealand Journal of Zoology 12: 17-53.

Moncrieff, P. (1932). "Notes on the South Island robin." Emu 32: 52-58.

Murray, A. L., A. M. Barber, et al. (2006). "Competitive environment affects foodhoarding behavior of Merriam's kangaroo rats (Dipodomys merriami)." Journal of Mammalogy 87(3): 571-578.

Onuki, Y., K. Kato, et al. (2005). "Influences of food type on food-carrying behavior in rats (Rattus norvegicus)." Behavioural Processes 70: 182-185.

Petit, K. E., L. J. Petit, et al. (1989). "Fecal sac removal: Do the pattern and distance of dispersal affect the chance of nest predation?" The Condor 91: 479-482.

Pielou, E. C. (1991). After the ice age: The return of life to glaciated North America. Chicago, University of Chicago Press.

Powlesland, R. G. (1980). "Food storing behaviour of the South Island robin." Mauri Ora 8: 11-20.

Powlesland, R. G. (1981). "The foraging behaviour of the South Island robin." Notornis 28: 89-102.

Powlesland, R. G. (1983b). "Breeding and mortality of the South Island robin in Kowhai Bush, Kaikoura." Notornis 30: 265-282.

Powlesland, R. G., J. W. Knegtmans, et al. (2000). "Breeding biology of North Island robins (Petroica australis longipes) in Pureora forest park." Notornis 47: 97105.

Pravosudov, V. V. (2006). "On seasonality in food-storing behaviour in parids: do we know the whole story?" Animal Behaviour In press.

Pruett-Jones, M. A. and S. G. Pruett-Jones (1985). "Food-caching in the tropical frugivore, MacGregors's bowerbird (Amblyornis macgregoriae)." The Auk 102: 334-341.

Rice-Oxley, S. B. (1993). "Caching behaviour of red squirrels Sciurus vulgaris under conditions of high food availability." Mammal Review 23(2): 93-100.

Roberts, R. C. (1979). "The evolution of avian food-storing behavior." The American Naturalist 114(3): 418-438. 
Smith, C. C. and O. J. Reichman (1984). "The evolution of food-caching by birds and mammals." Annual Review of Ecology and Systematics 15: 329-351.

Stevens, T. A. and J. R. Krebs (1986). "Retrieval of stored seeds by marsh tits Parus palustris in the field." Ibis 128: 513-525.

Tinbergen, N. (1953). Social behaviour in animals: with special reference to vertebrates. London, Methuen \& Co. Ltd.

van Horik, J. and K. C. Burns (2006). "Cache spacing patterns and reciprocal cache theft in New Zealand robins." Animal Behaviour In press.

Vander Wall, S. B. (1990). Food hoarding in animals. Chicago, The University of Chicago Press.

Vander Wall, S. B. and S. H. Jenkins (2003). "Reciprocal pilferage and the evolution of food-hoarding behavior." Behavioral Ecology 14(5): 656-667.

Yosef, R. and B. Pinshow (2005). "Impaling in true shrikes (Laniidae): a behavioral and ontogenetic perspective." Behavioural Processes 69: 363-367.

Young, B. E. (1994). "The effects of food, nest predation and weather on the timing of breeding in tropical house wrens." The Condor 96: 341-353. 